Running head: PROGRESSION BIAS ROMANTIC RELATIONSHIPS

We're Not That Choosy: Emerging Evidence of a Progression Bias in Romantic

Relationships

Samantha Joel

Western University

Geoff MacDonald

University of Toronto

In press at Personality and Social Psychology Review

Keywords: romantic relationships, decision making, mate selection, compatibility

Correspondence regarding this article should be addressed to Samantha Joel, Psychology

Department, Western University, 1151 Richmond Street, London Ontario, N6G 2 V4. 


\begin{abstract}
Dating is widely thought of as a test phase for romantic relationships, during which new romantic partners carefully evaluate each other for long-term fit. However, this cultural narrative assumes that people are well-equipped to reject poorly suited partners. In this paper, we argue that humans are biased toward pro-relationship decisions; decisions that favor the initiation, advancement, and maintenance of romantic relationships. We first review evidence for a progression bias in the context of relationship initiation, investment, and breakup decisions. We next consider possible theoretical underpinnings-both evolutionary and cultural-that may explain why getting into a relationship is often easier than getting out of one, and why being in a less desirable relationship is often preferred over being in no relationship at all. We discuss potential boundary conditions that the phenomenon may have, as well as its implications for existing theoretical models of mate selection and relationship development.
\end{abstract}




\section{We're Not That Choosy: Emerging Evidence of a Progression Bias in Romantic}

\section{Relationships}

Consider the very specific chain of events that must occur for a marriage to form in contemporary Western cultures. First, one of the partners must choose to pursue the other partner romantically. Any fears of being rejected that this person may have-as potent as rejection concerns are (e.g., MacDonald \& Leary, 2005)—must be overcome. If one person does not initially experience much physical attraction, passion, or sexual satisfaction with their partner, they must choose to overlook that concern, perhaps with the belief that such feelings will develop over time (Maxwell, Muise, MacDonald, Day, Rosen, \& Impett, 2017). If either partner encounters red flags or "dealbreakers" regarding their partner (e.g., Jonason, Garcia, Webster, Li, \& Fisher, 2015), those too must be overlooked in favor of the partner's positive qualities. Over time, both partners must mutually and continuously choose to invest in that particular relationship. A long and specific series of decisions is typically made, such as introducing the partner to friends and family, spending the night together, agreeing to become exclusive, planning future activities together, and eventually moving in together and/or getting engaged (Eastwick, Keneski, Morgan, McDonald, \& Huang, 2018). Finally, in the face of every relationship setback-every relationship-straining event that life may throw at the couple (e.g., Neff \& Broady, 2011) — both partners must choose to persevere rather than break up.

At every fork in the road-in the context of every relationship turning point—both partners must consistently make pro-relationship decisions. If each of these decisions was made at random - if every time a person faced a difficult decision about a romantic relationship, they resolved their dilemma on the basis of a coin toss-few relationships 
would ever begin, and the chances of any relationship making it through the first year would be incredibly small. And yet, approximately $80 \%$ of Americans over the age of 25 have been married at some point (Wang \& Parker, 2014), and forty-eight percent of Americans over 25 are currently married (Taylor, 2010). What are the mechanisms that lead people to make such a specific series of life decisions, so commonly?

We propose that so many romantic relationships are able to form and endure because humans have a bias toward pro-relationship decisions-decisions that serve to initiate, advance, and maintain romantic relationships-and against decisions that result in rejecting partners or forgoing romantic opportunities. In the current paper, we will use the term progression bias to refer to this general tendency to make decisions that move romantic relationships toward commitment (e.g., pursuing potential partners, agreeing to dates, and investing time and resources into the relationship) rather than dissolution (e.g., rejecting or breaking up with suitors). This phenomenon is likely underpinned by a broad collection of biological, social, cognitive, and affective mechanisms. Feelings of infatuation motivate people to spend time with prospective partners (e.g., Aron \& Aron, 1991; Eastwick \& Finkel, 2008; Hazan \& Diamond, 2000), and reward pathways activate in response to new partners (e.g., Acevedo \& Aron, 2014; Aon et al, 2005; Bartels \& Zeki, 2000; 2004; Burkett \& Young, 2012). In Western contexts, people experience social pressure to enter romantic relationships (DePaulo \& Morris, 2005; Day et al., 2011). Fears of long-term singlehood are common (Spielmann et al., 2013), and unpartnered people are subjected to stigma (e.g., Conley \& Colluns, 2002; Greitemeyer, 2009; Hertel et al., 2007; Morris et al., 2007). Even when a romantic partner or potential partner is undesired, rejecting them is difficult to do. Would-be rejectors often experience guilt (Bohns \& 
DeVincent, 2019; Baumeister, Wotman, \& Stillwell, 1993; Perilloux \& Buss, 2008) and concerns about hurting the suitor's feelings (Joel et al., 2014). In many non-Western contexts, it is common for people's self-selection into long-term relationships to be relatively limited, instead committing themselves to the partners chosen with strong influence from their parents or other family members (Apostolou, 2007; Buunk et al., 2010; Walker et al., 2011; Zaidi \& Shuraydi, 2002).

The progression bias runs counter to two common claims within established theoretical models within relationship science. First, it qualifies the field's current emphasis on the inhibiting role of rejection in relationship decisions (e.g., Bredow, Cate, \& Huston, 2008; Murray, Holmes, \& Collins, 2006; Shanteau \& Nagy, 1979). Existing theoretical models of relationship initiation and development (in Western contexts) suggest that people make pro-relationship decisions only when the risk of rejection is perceived to be low. We propose that, in fact, other motivational factors (e.g., the rewards of intimacy and caregiving, fears of missed romantic opportunities, social pressure) are sufficiently strong to motivate pro-relationship decisions even in the face of non-trivial rejection risks. The progression bias also contradicts the notion that commitment is a necessary precondition for pro-relationship biases (e.g., Fletcher, Simpson, \& Thomas, 1999; Rusbult \& Van Lange, 2003; 2008). Existing models of pro-relationship biases and positive romantic illusions stipulate that these biases primarily come online once commitment is high, after the relationship has become established. We propose that, in fact, these biases are present as soon as any romantic interest has developed, such that they play an important role in propelling fledging dating partners toward established partnerships. 
Below, we review emerging evidence for a progression bias across three major relationship turning points: initial mate choice, relationship investment, and stay/leave decisions. We will then discuss potential theoretical underpinnings of the phenomenon, including both evolutionary and social advantages, as well as implications for existing theoretical models of mate selection and romantic relationship development. Importantly, most of the evidence we review is subject to the same generalizability constraints as the discipline of psychology more broadly (e.g., WEIRD sampling; Henrich et al., 2010). We will discuss potential boundary conditions of the progression bias, including groups for whom the phenomenon may be stronger or weaker. Finally, we will conclude with suggested future directions, particularly highlighting the need for diverse recruitment as well as prospective methods that track real relationship experiences over time.

\section{Emerging Evidence of a Progression Bias}

\section{A Bias Toward Pursuit Over Rejection in Initial Dating Contexts}

How difficult is it to find suitable people to date? Many popular lay perspectives on dating assert that suitable dating partners are exceedingly rare-perhaps even a once-in-alifetime encounter (e.g., soulmates, or destiny beliefs; Knee, 1998). Yet, a growing body of research suggests that people are in fact open to dating a broad range of romantic partners. For example, in speed-dating contexts, participants tend not to be particularly selective in their matches, preferring instead to cast a wide initial net. In one study of over 10,000 speed daters, participants said yes to an average of $40 \%$ of their dating options $34 \%$ for women, $49 \%$ for men; Kurzban \& Weeden, 2007). In a recent pair of speed-dating studies with undergraduate students, participants' mean romantic liking for their dating options was at the midpoint of the scale (5 on a 9-point scale; Joel et al., 2017). Further, in these 
studies, people's choices about whether to match with a particular target were not calibrated to their romantic standards and ideals. In the former study, although people's advertised mate preferences predicted which speed-dating events people attended, they generally failed to predict people's desire for specific dates (Kurzban \& Weeden, 2007). In the latter pair of studies, machine learning methods were unable to predict any variance in relationship-level attraction using over 100 self-reported traits and preferences (Joel, Eastwick, \& Finkel, 2017). That is, although some individuals were broadly considered to be more desirable than others (e.g., physically attractive individuals were desired more), people's unique desire for certain individuals could not be predicted by their preferences (e.g., "I claim to prefer extraverts, and you are an extravert, so I desire you").

One possible explanation for these findings is that humans prefer a satisficing rather than optimizing approach to initial mate choice, such that people's mate preferences are more heavily swayed by the presence of dealbreakers (i.e., highly undesirable qualities) than they are by the presence of highly desirable qualities (Jonason et al., 2015; Long \& Campbell, 2015). Rather than exhaustively seeking out partners who uniquely fit one's ideals, people may instead begin by weeding out individuals who fail to meet minimum standards. In support of this idea, one study compared women's use of "accept-the-best" mate selection strategies - the approach of exhaustively searching for the most ideal partner-versus "reject-the-worst" strategies, whereby people reject unsuitable partners until they find a person who is minimally acceptable (Long \& Campbell, 2015). Single, heterosexual women were presented with a man who was either just above (accept-thebest condition) or just below (reject-the-worst condition) their stated dating standards on various traits. Participants were presented with one trait at a time, and could choose to 
request more information about the potential partner-up to 25 traits-before accepting or rejecting a date with that person. Results showed that participants who were presented with a person who fell below their dating standards requested significantly more information before making their decision compared to those whose potential partner exceeded their standards. That participants are more deliberative when choosing to reject than accept suggests that participants perceived rejecting a suitable partner to be a costlier error than accepting an unsuitable one.

Yet even when a potential suitor clearly fails to meet stated dating standards, people are still not particularly good at rejecting them. One pair of experiments showed that people's dating preferences can become less strict after a single live interaction with a potential dating partner (Eastwick, Finkel, \& Eagly, 2011). In these studies, participants rated their interest in a written dating profile that included either two of their most essential traits (ideal condition), or two of their least essential traits (unideal condition). Predictably, romantic interest was significantly higher when the profile matched their ideals compared to when it did not. However, participants then had a live interaction with an attractive confederate who was ostensibly the author of the dating profile. When participants rated their romantic interest in the potential partner a second time, romantic interest was similarly high regardless of whether the written profile matched their ideals or not. This was because those in the unideal condition became significantly more interested after the live interaction. In other words, although people discerned between potential partners who did versus did not meet their ideals when evaluating them "on paper," that selectivity vanished after a single interaction with the person. 
Not only do negative traits often fail to diminish people's romantic interest in potential partners, but negative traits in desired potential partners can even motivate people to adopt those negative traits into their own self-concepts (Slotter \& Gardner, 2012). In one experiment, single, heterosexual participants were presented with a profile of a physically attractive opposite-sex participant. The student was described with four personality traits, one of which the participant had previously rated as being negative and not characteristic of themselves. Participants rated the target negative trait as being more characteristic of themselves after seeing the profile compared to the pre-testing session, only if the profile was presented in a romantic context. A follow-up study revealed that this effect extended only to moderately negative traits (e.g., disorganized, clumsy), rather than severely negative traits (e.g., dishonest, selfish), and only when the potential partner expressed self-acceptance about the trait, rather than a desire to change. These results suggest that participants were willing to adopt a potential partner's negative traits into their own self-concepts specifically when doing so seemed likely to increase their own desirability to that person.

In a direct test of people's relative preference for initiating new relationships, another pair of experiments showed that people overestimate their willingness to reject unsuitable potential partners (Joel, Teper, \& MacDonald, 2014). In these studies, single undergraduate students were presented with dating profiles that ostensibly belonged to other single students. After selecting their favorite profile and learning that this student had chosen them in return, participants received new information suggesting that this student was unsuitable as a dating partner. In the first study, the profile was paired with an unattractive photo, and in the second study, the profile was paired with 2-3 traits that the 
participant had identified as personal dealbreakers at the beginning of the semester (e.g., very liberal, very conservative, very religious, not at all religious). Participants were randomly presented with this dilemma either as a hypothetical scenario or as an ostensibly real dating situation. Among participants who believed the scenario was hypothetical, $84 \%$ of participants said that they would reject the unattractive student (Study 1), and 54\% said that they would reject the incompatible student (Study 2). However, among participants who believed that the dilemma was real, only $63 \%$ of participants rejected the unattractive date, and only $26 \%$ of participants rejected the incompatible date. The results of the second study are particularly striking: nearly three quarters of participants agreed to a date with a person who possessed at least two of their own personal dealbreakers, suggesting that rejecting people who fail to meet one's dating standards is easier said than done.

These lab studies suggest that people do not merely have weak or malleable dating preferences, but in fact have a bias in favor of romantic pursuit. Once people believe that they are being presented with a real dating opportunity, they become more favorable toward the romantic target than they otherwise would be. Indeed, one of the first experiments to provide direct evidence for motivated reasoning generally was conducted in the context of attraction (Berscheid, Graziano, Monson, \& Dermer, 1976). In this study, participants were first asked to agree to date a pre-assigned individual for five weeks. Next, they watched a videotaped discussion among three individuals, and were told that one of those individuals was the person who they would be dating. Participants rated their randomly assigned date as significantly more attractive and liked them significantly more than the other individuals in the video. Although the sample size of this study was small (N 
$=54$ ), this ecologically realistic experiment provides some of the earliest evidence that people evaluate even brand-new potential partners in a positively biased way.

One seeming exception to the idea of a progression bias is the prevalence and acceptability of casual sexual relationships. If people are generally biased toward romantic pursuit, why do people frequently seek to satisfy their sexual needs outside of romantic contexts? Intentionally or not, casual sexual relationships often function as a stepping stone to committed relationships rather than as a replacement for them. For example, users of Tinder (with a reputation as a hookup site; LeFebvre, 2017) who meet offline frequently transition to committed romantic relationships (Timmermans \& Courtois, 2018). Casual relationships that include both emotional closeness and sexual gratification such as friends-with-benefits (FWB) may be particularly likely to transition into committed partnerships. For example, in a longitudinal examination of 192 FWB relationships, $25 \%$ of the sample hoped for their FWB relationship to develop into a romantic relationship at Time 1, and 15\% of the sample were indeed dating their former FWB 11 months later (Machia et al., 2020). In another sample of 764 participants in exclusive dating relationships, 20\% indicated that their dating relationship had begun as a FWB relationship (Owen \& Fincham, 2012). Thus, despite the attempt to label these relationships as casual, people engaging in FWB relationships may well have been pulled along by the progression bias. Indeed, Park et al. (2020) found suggestive evidence that although singles who were more satisfied with their sex lives were less desirous of a romantic partner, they were nonetheless more likely to end up in a romantic relationship than those who were less sexually satisfied. Sexually active singles finding themselves transitioning into committed relationships despite relatively low desire for a relationship 
may occur, in part, because casual relationships tend to follow a particular sequence of early relationship events in a way that is essentially indistinguishable from long-term relationships (Eastwick et al., 2018). Thus, although it is certainly not the case that every sexual encounter has the potential to become a committed partnership, those labelling their relationships as casual are not necessarily immune from forces that we argue exert a strong pull towards greater investment and commitment.

The idea that people are open to pursuing a broad range of dating partners-and reluctant to let go of potential romantic opportunities-helps to explain why researchers have traditionally been so successful at capturing attraction and romantic love empirically. For example, in one classic study, single undergraduate students were recruited and their experiences of falling in love were tracked over the course of a semester (Aron, Paris, \& Aron, 1995). Of the undergraduate students recruited for the two longitudinal studies, $33 \%$ of participants in Study 1 fell in love over the course of a 12 -week period, and $26 \%$ of participants in Study 2 fell in love over the course of a 10-week period. Descriptive data such as these suggest that, far from being a rare experience, falling in love is common enough that researchers need only recruit a sample of single undergraduate students and wait for it to occur.

Overall, research on initial romantic attraction suggests that it is not as hard as it may seem to motivate people to start a dating relationship. Attraction is by no means a rare experience (Aron et al., 1995), and feelings of attraction can be reliably generated with confederates in laboratory contexts (Berscheid et al., 1976; Eastwick et al., 2011; Slotter \& Gardner, 2012). Stated romantic standards are not good predictors of romantic interest (Joel et al., 2017; Kurzban \& Weeden, 2007), and people struggle to reject suitors who 
explicitly do not meet their stated dating standards (Eastwick et al., 2011; Joel et al., 2014;

Slotter \& Gardner, 2012). Further, even relationships that are initially perceived as or intended to be casual frequently transition into committed romantic relationships (Machia et al., 2020; Owen \& Fincham, 2012; Timmermans \& Courtois, 2018).

\section{A Bias Toward Progression Over Rejection in New Dating Relationships}

Together, the above studies cast doubt on the idea that people are particularly selective in the initial stages of a romantic relationship. However, most of these studies examine people's romantic interest in individuals that they have either never met or have known for a relatively brief period. Might it be that greater partner selectivity tends to occur in later stages of dating? That is, perhaps people cast a wide net when first considering whether to date someone, and then use later interactions to gradually determine whether that person is a good long-term fit or not.

The dating phase is when romantic partners become heavily emotionally invested in each other. Attachment theory posits that romantic partners bond with each other via the attachment system. Once a romantic partner becomes an attachment figure (i.e., relied on as a primary source of validation and support; Hazan \& Shaver, 1987), rejecting that relationship should be substantially more painful and difficult compared to before the attachment bond has formed (LeRoy, Knee, Derrick, \& Fagundes, 2019). Indeed, it has been argued that the very evolutionary purpose of adult attachment bonds is to motivate parents to remain as a unit for long enough to co-raise their offspring (e.g., Fraley, Brumbaugh, \& Marks, 2005). Drawing on this work, the "trial period" of a new romantic relationship - the period in which a person has the option of rejecting a new partner 
without experiencing an intensely painful breakup—should last only as long as it takes for an attachment bond to form.

Early research suggested that this pre-attachment period lasts about two years, which is a common courtship length in Western culture. For example, in one study on adolescent relationships, participants in relationships that had lasted more than two years reported stronger attachment to their partners, on average, than those in shorter relationships (Hazan \& Zeifman, 1994). However, more recently, when researchers examined romantic attachment formation directly in a longitudinal study of adults (mean relationship length of 16.31 months), they did not find any evidence that attachment to romantic partners increased over the course of a year (Heffernan, Fraley, Vicary, \& Brumbaugh, 2012). Instead, many participants were already strongly attached to their partners at the time they began the study. A large cross-sectional study further qualified these results: not only were there no differences in attachment strength between people in established ( 2 years plus) versus newer relationships, but even among participants in brand new relationships (fewer than three months), approximately $76 \%$ already used their partners for proximity-seeking, approximately $58 \%$ used their partner as a safe haven, and approximately $49 \%$ used their partner as a secure base. Another study following people in new relationships obtained similar results (Fagundes \& Schindler, 2012). Although use of the partner as a secure base did continue to increase over the first two years of the relationship, most of the increase in proximity seeking and use of the partner as a safe haven occurred before the participants had even entered a formal, exclusive relationship with their partners. 
These findings suggest that people tend to develop meaningful attachment bonds with romantic partners within the first few months of dating; a much shorter time frame than has previously been assumed. If true, this means that the first few months of a dating relationship are critical for evaluating a romantic partner's long-term fit. Considerably less attention has been paid to the early stages of a romantic relationship compared to initial romantic attraction and established relationship maintenance (Joel \& Eastwick, 2018). The limited longitudinal work available suggests that, although people do evaluate new dating partners for long-term fit, people are also biased in favor of relationship progression even in these very early dating stages.

In one ambitious study, 100 participants were recruited during the first four weeks of dating and tracked over a one-year period (Fletcher, Simpson, \& Thomas, 2000). Whereas 78 participants were still dating the same person by the second month, only 54 were still with the same person by the third month. Clearly, some level of partner evaluation and selection occurred over this initial dating period. And indeed, participants were particularly likely to evaluate the dating partner positively and remain in the relationship over time to the extent that the partner met their ideal standards. Similar results were found in more recent studies in which researchers managed to track participants from before they even entered their new relationships (Campbell, Chin, \& Stanton, 2016; Gerlach, Arslan, Schultze, Reinhard, \& Penke, 2019). In the largest such study to date, a total of 763 single individuals were followed over five months, $34 \%$ of whom entered a new dating relationship in that time (Gerlach et al., 2017). The researchers found that for those who entered new relationships, ideal partner preferences as reported when single did predict participants' later reports of their new dating partners' 
characteristics. These studies suggest that people do evaluate new dating partners based on a set of ideal standards. Yet, even in these first few months of the relationship, people also adjusted their ideal standards to fit the romantic partners they had. In the Gerlach et al. study (2019), participants who rated their new partners as falling short of their initial ideals tended to adjust their preferences downward. Similar results were found in the Fletcher et al. study (2000): when people perceived their dating partner to be higher on a given ideal partner dimension, that dimension was subsequently rated as being more important.

Bonds with new partners may continue to strengthen even when signs of incompatibility are present. In another recent longitudinal study, 78 newly dating couples (average relationship length of 3 months) were recruited and surveyed about their current goals, goal importance, and the degree to which their goals conflicted with their partner's goals (Gere \& Impett, 2017). A total of 59 of these new couples (76\%) were still together three months later. Further, the researchers found that the more that a particular goal a person had conflicted with the partner's goals, the more that person tended to devalue that goal over time, which in turn was generally associated with relationship benefits. This study provides some preliminary evidence that, rather than reject new relationships that conflict with one's goals, people may be more inclined to shift their goals to better align with the new relationship.

In addition to becoming intertwined emotionally, the dating phase is also when couples make a series of joint investments, such as integrating into each other's social networks, moving in together, and getting married. These investments cause the partners' lives to be more intertwined pragmatically, making a breakup more logistically difficult. 
Indeed, investment is one of the best predictors of whether a dating relationship will remain intact (Le \& Agnew, 2010). Thus, one important way for people to be selective in their choice of long-term partners would be to invest in new relationships slowly and cautiously, as they gather information about whether their new partner is the right longterm partner for them. Yet, emerging research suggests that the decision processes that underlie key relationship investments tend not to be very cautious or deliberative.

The specific investment that has received the most empirical attention is the decision to move in with a romantic partner: a concrete investment that strongly increases the barriers to exiting the relationship and that is often framed as a precursor to marriage. Qualitative work suggests that people often choose to move in with their romantic partners relatively early on in the dating process. In an interview study of 25 cohabiters in New York City, 13 (52\%) had moved in together within six months of dating (Sassler, 2004). In a larger study of 122 cohabiters, $36 \%$ of the sample had moved in within six months of dating (Sassler \& Miller, 2011). Although participants often report cohabiting for relationship-related reasons (e.g., to spend more time together), people also often report cohabiting for reasons of convenience (e.g., because it makes sense financially; Rhoades, Stanley, \& Markman, 2009; Sassler \& Miller, 2011). For many, moving in together is not a conscious decision at all, but is rather a gradual, almost accidental process (Lindsay, 2000; Manning \& Smock, 2005; Sassler, 2004). In one study, researchers conducted in-depth interviews of 115 young adults who had recently moved in with their romantic partners (Manning \& Smock, 2005). The interviews revealed that for at least half of the sample, moving in with the romantic partner was a gradual transition; something that slowly 
happened over time as one romantic partner began spending more and more time in the other person's living space.

Moving in together, in turn, may increase the pragmatic difficulties of exiting the relationship, leading dating couples to stay together and eventually "slide" into marriage when they otherwise may have dissolved their relationships (Stanley, Rhoades, \& Markman, 2006). This inertia effect—whereby early investments in a relationship make it difficult to exit that relationship later on, even if it is low quality—may help to explain why cohabitation before marriage is associated with higher divorce rates, but only among couples who move in together prior to getting engaged (Kline, Stanley, Markman, OlmosGallo, Peters, Whitton, \& Prado, 2004; Rhoades, Stanley, \& Markman, 2009).

Further evidence suggests that investment in new dating relationships has a reciprocal quality (Joel, Gordon, Impett, MacDonald, \& Keltner, 2013). In a longitudinal study, 69 couples with an average relationship length of 16 months were surveyed each day for two weeks about their partner's sacrifices for the relationship. People whose partners made more daily sacrifices experienced increased commitment to their relationships three months later, an effect that was not moderated by relationship satisfaction. Similar effects were obtained in an experimental study: people randomly assigned to think about their partner's relationship investments consequently felt more committed to their relationships, even if (in fact, especially if) they were not particularly satisfied with their relationships. These results suggest that contributions to the relationship that are made by one romantic partner can motivate further contributions from the other partner, even if that person perceives the relationship to be relatively unsatisfying or low-quality. 
In sum, the evidence accumulated thus far suggests that people struggle to remain selective and discerning during the early dating stages of a relationship. Emotional investment in terms of attachment to romantic partners appears to emerge much more quickly than researchers have previously believed (Heffernan et al., 2012). Although new partners are preferred to the extent that they meet one's standards, standards are also adjusted to be more aligned with the traits of new partners (Fletcher et al., 2000; Gerlach et al., 2019), and people may be motivated to persevere with new relationships even in the face of potential incompatibilities (e.g., incongruent goals; Gere \& Impett, 2017). Further, couples often "slide" into major investments into the relationship-those that increase the pragmatic difficulty of exiting the relationship-quite early in the relationship and with little conscious deliberation (Lindsay, 2000; Manning \& Smock, 2005; Sassler, 2004; Stanley, Rhoades, \& Markman, 2006). Taken together, emerging research in the field suggests that new dating couples tend to become rapidly invested both emotionally and pragmatically, potentially with little deliberation and despite potential red flags.

\section{A Preference for Staying Over Leaving in the Face of Relationship Difficulties}

Ideally, all unsuitable potential partners and partnerships would be rejected either before the relationship ever began or when the relationship was still in its fledgling, formative stages. However, it is often the case that people do not realize until many months or years into a relationship that their romantic partner is not a good fit for them, or that the relationship that they have built is chronically unsatisfying or even unhealthy. In such a situation, it is still arguably best to end the relationship before further investments are made (e.g., marriage or children). However, ending an established romantic relationshipeven a dating relationship-is notoriously difficult to do. 
Building on interdependence theory (Thibaut \& Kelley, 1959), the investment model offers an elegant explanation for how and why people frequently persevere with unsatisfying relationships (Rusbult, 1980; 1983; Drigotas \& Rusbult, 1992). The investment model proposes that people are likely to remain in their relationships to the extent that they feel dependent on the relationship; i.e., to the extent that the relationship satisfies important needs better than an alternative relationship would. People do tend to feel more dependent on more satisfying relationships. However, people also tend to feel more dependent when they are highly invested in the relationship-when they have put a great deal into the relationship that would be lost if the relationship ended-as well as when they perceive few appealing alternatives to their relationship, such as other people who they could date. This dependence, in turn, leads to greater commitment to remaining in the relationship over time. Overall, the investment model argues that individuals who perceive that they are either highly invested or have a low quality of alternatives are likely to have great difficulty exiting the relationship, even if their satisfaction with the relationship is low. A large body of longitudinal work supports this model. For example, a meta-analysis of 202 samples $(N=50,427)$ found that alternatives and investment emerged as independent predictors of commitment, above and beyond relationship satisfaction (Tran, Judge, \& Kashima, 2018). Commitment, in turn, is a strong predictor of choosing to remain in the relationship (Le \& Agnew, 2003).

This aversion to ending existing relationships has also been uncovered in hypothetical contexts, even when attractive alternatives are available (Gunaydin et al., 2018). In a series of vignette studies, participants were asked whether they would choose to end a 3-month-long relationship for the opportunity to date a more attractive partner. 
Participants showed a robust status quo preference, preferring to remain with the existing partner rather than switch to a more attractive new partner. Mechanisms that helped to explain this preference included concerns about hurting the potential partner, and uncertainty surrounding the alternative relationship.

The many challenges to ending romantic relationships are particularly sobering in the context of abusive relationships, which are alarmingly common among dating couples. In one meta-analysis, $38 \%$ of women and $42 \%$ of men across studies were reportedly physically aggressive toward their partners (Archer, 2000). Even these unhealthy relationships can be very difficult to dissolve, as people frequently feel committed to their partners despite the presence of aggression (e.g., Arriaga, 2002; Arriaga, Capezza, Goodfriend, Rayl, \& Sands, 2013). In one study, 100 women were interviewed upon their arrival at a shelter for domestic violence (Rusbult \& Martz, 1995). Most of these women had suffered severe physical abuse from their partners (e.g., $94 \%$ described their partners as "dangerous"), yet $65 \%$ returned to their partners over the following 12 months. As predicted by the investment model, those who returned to their partners had reported lower quality of alternatives and higher investment, and in turn higher commitment, compared to those who did not.

Unlike decisions that move a relationship forward (e.g., cohabitation), breakup decisions appear to involve a relatively drawn-out, deliberative process. In one study, undergraduate students were asked to list the steps that occur when a relationship dissolves, which the researchers then combined into a normative "script" for relationship dissolution (Battaglia, Richard, Datteri, \& lord, 1998). The resulting script revealed a cyclical process whereby multiple attempts are made to work things out before the 
relationship eventually ends. Dissolution consideration —-whereby people spend time actively contemplating whether they should exit the relationship-appears to be a critical part of this breakup process, linking low commitment to actual leave behavior (VanderDrift, Agnew, \& Wilson, 2009). Further evidence suggests that decision conflict is common among people who are thinking about ending their relationships. In a recent pair of studies, participants currently thinking about ending their relationships were surveyed about their decision processes (Joel, MacDonald, \& Page-Gould, 2017). Although participants tended to endorse many reasons for wanting to end their relationships (e.g., emotional distance, traits they disliked about their partner, the perception that they were incompatible with their partners), they simultaneously endorsed many reasons for wanting to stay in their relationships (e.g., traits they liked about their partner, companionship that they derived from the relationship). These results suggest that "low" commitment to a relationship may frequently be experienced as ambivalence, whereby the positive aspects of the partner and the relationship remain salient to the decision maker even as they are actively thinking about initiating a breakup.

When people do decide to initiate a breakup, they often experience guilt regarding the impact that the decision will have on the partner (Perilloux \& Buss, 2008), and many breakup initiators select breakup strategies intended to soften that impact (Collins \& Gillath, 2012). Yet, the breakup recovery process may be just as painful for the partner who does the rejecting as it is for the partner who is rejected, as evidenced by null effects of initiator status on breakup recovery over the course of a 28-day diary study (Sbarra, 2006). Even after a relationship is dissolved, the breakup does not always "stick". On-again/offagain relationships are common, whereby a relationship dissolves and renews, often 
repeatedly (Dailey, Rossetto, Pfiester, \& Surra, 2009). For example, in one sample of 445 college students, $62 \%$ reported having experienced at least one on-again/off-again relationship as part of their dating history, most of which included multiple cycles of breakups and renewals (Dailey, Pfiester, Jin, Beck, \& Clark, 2009).

\section{Why Do People Show a Progression Bias?}

In sum, decisions that help people to begin, advance, and maintain romantic relationships may feel easier than decisions that curtail those relationships. The emerging research on relationship decision processes suggests that decisions to pursue new romantic partners tend to be made with less discretion than previous theorizing has suggested, decisions to invest in relationships tend to be made rapidly and intuitively, and decisions to end relationships tend to be effortful and painful. Why do people struggle so much to reject romantic partners, even when those partners are strongly misaligned with their standards and long-term goals? We argue that this phenomenon occurs because decisions that favor being in a romantic relationship—any romantic relationship—are underpinned by evolved mechanisms forged during historical epochs of partner scarcity and reinforced by current social structures.

\section{Explanation 1: Choosing a Partner Relatively Unselectively Is Evolutionarily} Advantageous

Humans have evolved a somewhat unusual tendency to form long-term pair bonds with our mates (Fletcher et al., 2015; Fraley et al., 2005). Yet, for our ancestors to survive and pass on their genes, securing a minimally acceptable romantic partner may still have been considerably more important than finding an ideal partner. Especially in the context of relatively small social groups wherein people were in competition for a limited number 
of mates (Dunbar, 1992), being relatively unselective may have been a more adaptive strategy than holding out for the best possible partner. In support of this idea, agent-based simulation studies have shown that "fast and frugal" mate search strategies are more likely to result in finding a mate compared to more complex, quality-driven strategies (Neth, Schachtele, Duwal, \& Todd, 2011; Todd, 1997). If winding up without a long-term partner has historically led to lower rates of reproduction than winding up with a low-quality partner, then selection pressures should have favored motivation to form long-term romantic attachments with minimally suitable partners. People who wish to carefully select a compatible long-term partner may thus be fighting against evolutionary pressures to find and bond with a partner quickly.

Further support for a fast and frugal approach to mate choice-people's tendency to try to satisfice with a minimally acceptable partner, rather than maximize with the best possible partner - can be found in the sex ratio literature. Drawing on both evolutionary and social exchange perspectives, researchers have generally predicted people's mate standards to increase when potential mates are abundant and decrease when mates are scarce (see Stone, 2019 for review). In other words, assuming that people follow a maximizing principle of trying to obtain the best possible partner, people should be choosiest when they have the most mates to choose from. Yet, evidence for this intuitive pattern has been surprisingly mixed. For example, when a given society has a high sex ratio (more men than women), men face more competition for mates, and vice versa for women in low sex ratio societies (Guttentag \& Secord, 1983). Yet, in a study of 9809 participants across 36 cultures, sex ratio was generally unrelated to men's stated mate standards, whereas women, if anything, had lower stated standards in societies with more rather than 
fewer men (Stone et al., 2007). These findings are inconsistent with the idea that people exhaustively seek out the best possible mate, and instead suggest a fast and frugal approach to mate choice. Mating standards come online precisely when options are scarce rather than plentiful because the purpose of having mate standards is to uphold a minimum standard of acceptability.

One specific, biologically based mechanism that may motivate pro-relationship decisions is infatuation. The early stages of a relationship are typically characterized by intense feelings of passion, or infatuation (Tennov, 1979); relationship researchers have long theorized that the evolutionary purpose of these feelings is to motivate people to dedicate enough time and energy to the new relationship to allow a long-term attachment to form (Diamond, 2003; Fletcher et al., 2015; Hazan \& Diamond, 2000; Zeifman \& Hazan, 1997). That is, once an attractive potential partner has been identified, the attachment and sexual systems powerfully drive people to become closer to that person, both psychologically and physically (Aron \& Aron, 1991; Fisher, 1998; Gonzaga, Keltner, Londahl, \& Smith, 2001). For example, thinking about a new dating partner activates the attachment system, which motivates people to seek proximity to that person (Eastwick \& Finkel, 2008). Sexual desire has also been shown to motivate behaviors that advance new relationships, such as the disclosure of thoughts and feelings (Birnbaum, Mizrahi, Kaplan, Kadosh, Kariv, Tabib et al., 2017; Gillath, Mikulincer, Birnbaum, \& Shaver, 2008), not to mention the intimacy-promoting behavior of sex itself (e.g., Birnbaum \& Gillath, 2006). Thus, simply by pursuing the natural rewards of spending time with an attractive new partner or potential partner, people may set the stage for long-term relationship formation whether they consciously intend to do so or not. 
Consistent with this reward-based perspective, recent neurobiological research shows that romantic love shares much of the neural circuitry associated with addiction (Acevedo \& Aron, 2014; Burkett \& Young, 2012). Several functional neuroimaging studies have shown that viewing photos of a new romantic partner leads to heightened activation in the caudate nucleus and the ventral tegmental area (Aron, Fisher, Mashek, Strong, Li, \& Brown, 2005; Bartels \& Zeki, 2000; 2004): two dopamine-rich brain regions that are important for reward-based learning and behavior (e.g., Carter, Macinnes, Huettel, \& Adcock, 2009; Haruno, Kuroda, Doya, Toyama, Kimura, Samejima et al., 2004). The links between these brain regions and romantic love have been replicated cross-culturally $(\mathrm{Xu}$, Aron, Brown, Cao, Feng, \& Weng, 2011), and with use of different stimuli (subliminal presentation of the partner's name instead of a photo; Ortigue, Bianchi-Demicheli, Hamilton, \& Grafton, 2007). In several studies, activation of the caudate in particular was greater among participants who reported more passionate love for their partner (Acevedo, Aron, Fisher, \& Brown, 2012; Aron et al., 2005; Ortigue et al., 2007). The centrality of reward systems for pair-bonding is also evident in animal models (e.g., Burkett, Spiegel, Inoue, Murphy, \& Young, 2011; Johnson \& Young, 2015); for example, in a study examining dopamine transmission in male prairie voles, activation of D2-like receptors in the nucleus accumbens promotes the development of a preference for a specific mate, whereas D1-like receptors promote the rejection of new potential mates (Aragona, Liu, Yu, Curtis, Detwiler, Insel, \& Wang, 2006).

Endogenous opioids may also play an important role in promoting and maintaining social attachments (brain opioid theory of social attachment; e.g., Inagaki, 2018; Panksepp et al., 1980; Panksepp, 1998). For example, participants who have been experimentally 
administered naltrexone-an opioid receptor antagonist—have been found to subsequently experience less social connection in daily life (Inagaki et al., 2016), and to expect and desire less social reward from new interaction partners (Tchalova \& MacDonald, 2020). Notably, if forming an attachment to a person is akin to forming a physical dependence on an exogenous drug, then severing that attachment bond should elicit intense withdrawal (see Machin \& Dunbar, 2011; LeRoy et al., 2019 for reviews). The loss of a loved one is theorized to trigger an abrupt cessation of opioid release, leading the person to experience separation distress and motivating them to try to re-establish their lost connection (Panksepp \& Watt, 2011). Indeed, even temporary separation from a romantic partner is associated with physiological dysregulation (Diamond, Hiks, \& OtterHenderson, 2008). Thus, it is likely not only the presence of reward that motivates relationship persistence, but also the potential pain of the loss of that reward. Consistent with this idea, one circumstance that increases the likelihood of relationships ending is the presence of attractive alternatives (South, Trent, \& Shen, 2001; South \& Lloyd, 1995), suggesting that breakups are more likely when the emotional dysregulation can be attenuated by finding (or already being in) a new relationship (Spielmann, MacDonald, \& Tackett, 2012).

In sum, humans appear to be satisficers-not maximizers—when it comes to mate search. Despite the virtually limitless number of mates that modern-day singles have to choose from, our motivational systems are not well-equipped to evaluate all of those options exhaustively and thoroughly (Lenton, Fasolo, \& Todd, 2008; Lenton \& Francesconi, 2010; Wu \& Chiou, 2009). Rather, selection pressures would arguably have favored motivational systems oriented towards quickly seeking out and securing a minimally 
suitable partner (e.g., Neth et al., 2011). Once such a partner has been identified, reward (i.e., infatuation, sexual desire) and punishment (i.e., withdrawal of dopamine and opioids) based processes powerfully motivate investment into that relationship via behaviors such as spending time with the partner (Eastwick \& Finkel, 2008) and disclosing thoughts and feelings to the partner (Birnbaum et al., 2017). Investment promotes commitment, and in turn stability (Rusbult, 1980; 1983), even if the relationship becomes unfulfilling (Joel et al., 2013; Le \& Agnew, 2003; Rusbult, 1983) or unhealthy (e.g., Rusbult \& Martz, 1995).

\section{Explanation 2: Entering a Relationship Confers Social Benefits}

A second, not-mutually-exclusive explanation for why people show a progression bias in romantic relationships is that relationships are socially beneficial. Although many of the social needs discussed in the previous section could be met in a number of types of relationships, modern Western culture upholds the romantic relationship as a being a particularly central and meaningful close relationship. Romantic relationships are upheld in Western society as more important than other kinds of social bonds, and entering a longterm romantic union (particularly through marriage) is considered to be an important life milestone. Life within a committed partnership is presumed to be more satisfying, meaningful, and complete than life outside of one. These pro-relationship beliefs have been collectively referred to by scholars as the ideology of marriage and family (DePaulo \& Morris, 2005), or as committed relationship ideology (Day, Kay, Holmes, \& Napier, 2011), and are posited to be pervasive and largely unchallenged, including within the field of relationship science.

Within this pro-relationship belief system, being in a committed relationship is taken as an indicator of success and maturity. A corollary of this perspective is that people 
who are uncoupled are less successful and less mature. Indeed, single individuals are subjected to stigma. In one series of vignette studies, single targets were perceived to be less responsible, more risky, more promiscuous, and less honest and sincere than coupled targets (Conley \& Collins, 2002). Similar studies have found that single targets are rated as being more miserable and lonely, less warm and caring (Hertel, Schutz, \& DePaulo, 2007), less attractive, less satisfied with their lives, worse on all the Big Five traits (e.g., less agreeable, more neurotic), and as having lower self-esteem (Greitemeyer, 2009), compared to when those same targets were described as being in committed relationships. These perceived differences emerge despite the fact that the personalities of single versus partnered individuals do not appear to differ, either when rated by the self or by observers (Greitemeyer, 2009). In addition to being negatively stereotyped, single individuals may be discriminated against. In another series of experiments, participants were asked to choose which hypothetical tenant they would rent a house to (Morris, Sinclair, \& DePaulo, 2007). Participants overwhelmingly chose to rent to married couples over other potential tenants (e.g., single women, single men, cohabiting couples, and pairs of friends), including one sample of participants who currently worked at rental offices. Some types of discrimination against single individuals are arguably systemic, such as spousal Social Security benefits in the United States (see DePaulo \& Morris, 2005 for review).

If being in a romantic partnership confers a wellspring of societal benefits that are independent from the quality of the relationship itself, that may help to explain why people often feel compelled to pursue and persist with romantic partners even without strong feelings of romantic interest. Fears around singlehood are normative; in a series of studies, both single and coupled individuals from both undergraduate and community samples 
tended to endorse items like, "It scares me to think that there might not be anyone out there for me", and "If I end up alone in life, I will probably feel like there is something wrong with me" at above the midpoint of the scale (Spielmann, MacDonald, Maxwell, Joel, Peragine, Muise, \& Impett, 2013). Across these studies, people with a particularly strong fear of being single were broadly less selective in their approach to relationship decisions: they were open to dating a broader range of partners in both hypothetical and real dating contexts, and they were less likely to choose to end unsatisfying relationships, compared to individuals with less fear of singlehood (Spielmann et al., 2013). For example, in one study, single participants were recruited for speed-dating events. Participants with a stronger fear of being single expressed romantic interest in a greater number of dating options, an association that was mediated by avoidance goals (e.g., "to avoid being alone"). These effects emerged despite the fact that people with a stronger fear of being single were no less desirable, as indicated by other daters' romantic interest in them, than people with less fear of singlehood (nor are they less physically attractive; Spielmann, Maxwell, MacDonald, Peragine, \& Impett, 2020).

Together, this research suggests that being in a romantic relationship confers a broad range of social and societal benefits that go beyond the immediate, intrinsic rewards of the relationship itself. The perception that simply being in a romantic partnership holds enormous value-both for the self and for the partner-may motivate people to advance and maintain relationships even when feelings of romantic interest are weak or even absent. 


\section{Theoretical Implications of the Progression Bias}

The idea that people generally prefer to advance romantic relationships rather than reject them runs counter to the way that relationship researchers have so far been conceptualizing interdependence in two ways. First, multiple theoretical models imply that decisions that increase interdependence with a romantic partner should be relatively rare, because they require a person to risk the pain of rejection. We propose that such models may be improved by considering the role of other rewards and costs that may skew cost/benefit calculations in favor of pro-relationship choices despite rejection risks.

Second, theoretical models of relationship evaluation have generally assumed that pro-relationship biases do not come online until after a commitment to the partner has already been made. We propose that, in fact, pro-relationship biases are present from the very start of a relationship, helping to facilitate commitment to new romantic partners in the first place.

\section{Implications for Interdependence Dilemmas}

Building on the idea that people make decisions that maximize reward and minimize costs (social exchange theory; Thibaut \& Kelley 1959), several theoretical models present relationship decisions as a dilemma between the rewards of connectedness and the costs of rejection. As an example, one popular conceptualization of romantic pursuit decisions can be formalized as follows (Bredow et al. 2008; see also Shanteau \& Nagy, 1979):

$$
V=f(A \times P)
$$

Where $\mathrm{V}$ is the likelihood of making a romantic overture toward a target, $A$ is attraction toward the target, and $P$ is the probability that the target will accept the overture rather 
than reject it. This formula assumes that the key motivational factors involved in a pursuit decision are the rewards of attraction and the costs of rejection, and that the two factors are equally weighted. Based on this model, pursuit decisions should be relatively uncommon, as people should be sufficiently motivated to make a romantic overture only when attraction is high and when likelihood of rejection is perceived to be low.

Relatedly, the risk-regulation model puts forth an elegant system with which people evaluate their likelihood of rejection in a given relationship context (Murray, Holmes, \& Collins, 2006). When deciding whether to risk interdependence—such as by self-disclosing, confessing one's feelings, or leaning on a partner for support-people look for cues that their partner cares for them and is willing to strive to meet their needs. If the partner's regard for the self is deemed to be high, then trust in the partner is high, perceived likelihood of rejection is low, and relationship promotion goals can be prioritized. However, when the partner's regard for the self is in question, protection goals should be prioritized and dependence on the partner should be minimized. For people with lower self-esteem, potentially threatening relationship situations are particularly likely to activate the goal of minimizing dependence and protecting the self (e.g., Cavallo et al., 2012; Murray, Derrick, Leder, \& Holmes, 2008). This model has been tested primarily in the context of day-to-day decision dilemmas within the context of established relationships. However, it is posited to apply to larger relationship decisions and turning points as well, such as whether to ask someone out on a date or whether to get engaged (Murray et al., 2006).

Both of these models imply that connectedness goals and rejection goals are equally weighted, such that people will only increase their dependence on a romantic partner if 
they are relatively confident that they can avoid rejection in the process. However, these models are inconsistent with emerging data suggesting that macro-level relationship decisions tend to be biased in favor of the relationship. For example, in the context of romantic pursuit, people frequently choose to pursue romantic partners even when their own fears of rejection are high (e.g., those with high attachment anxiety; McClure et al., 2010), even when their perceived chances of rejection are high (e.g., Joel et al., 2019), and even when attraction is not particularly strong (e.g., Spielmann et al., 2013). We propose that these effects emerge in part because the rewards of intimacy may be weighted more strongly than the costs of rejection (Gere et al., 2013), and also because the cost/benefit calculations that comprise romantic pursuit decisions include additional rewards beyond intimacy (e.g., the many social benefits one derives from being in a relationship) and additional costs beyond rejection (e.g., the risk of winding up without a partner) that nudge people toward pursuing rather than not pursuing.

\section{Implications for Relationship Standards}

Other theoretical models of partner selection include an evaluative component: how do people arrive at an overall judgment of whether the relationship (or potential relationship) is good or bad? These models typically incorporate some level of prorelationship bias, building on the large body of literature showing that people tend to view their romantic relationships with rose-colored glasses (see Gangé \& Lydon, 2004; Fletcher \& Kerr, 2010 for reviews). However, positive illusions are generally proposed to develop as a function of commitment, to help people maintain their established relationships over the long term. That is, the dominant theoretical perspective is that people evaluate potential partners relatively objectively to begin with, but then gradually become biased in favor of 
the relationship as it develops and as their lives become intertwined with their partners' lives.

The most prominent model examining the evaluation of romantic partners is the ideal standards model (Fletcher, Simpson, \& Thomas, 1999). Drawing on evolutionary perspectives as well as interdependence theory, the ideal standards model posits that people evaluate romantic partners along three key dimensions: warmth, attractiveness, and status/resources. People are proposed to be more interested in potential partners, and more satisfied with current partners, to the extent that they match one's ideals along these dimensions. The strength of the evidence for people's tendency to select partners who match their ideals is hotly debated (see Eastwick et al., 2019; Fletcher et al., 2020 for discussion), and is generally outside the scope of the current manuscript. More relevant to the current discussion is the component of the ideal standards model that concerns the degree of bias that people have when evaluating partners. In the context of long-term, committed relationships, people are theorized to be motivated to see their partners in a positive light, and may therefore adjust either their ideals or their perceptions of their partners to reduce any discrepancies. In contrast, when people are trying to make macrolevel decisions about their relationships, they are posited to prioritize accuracy goals and to perceive their partner in a more objective light: "However, when the need to make accurate, unbiased judgments becomes critical in relationships (such as when individuals must decide whether or not to date someone, get married, or have a child), the accuracy motive should take precedence" (Fletcher \& Simpson, 2000, p. 103).

This argument follows from the transformation of motivation component of interdependence theory, which holds that as romantic partners' lives become increasingly 
merged, their motivations will shift away from immediate self-interest and toward broader concerns about protecting the partner and the relationship (Rusbult \& Van Lange, 2003; 2008). Pro-relationship judgements and choices emerge as a function of one's interdependence with the partner: when two people are highly reliant on each other to meet important psychological needs, it is in everyone's best interests for the relationship to succeed, which motivates people to evaluate their partners in a positive light. In contrast, when romantic partners are not yet interdependent with each other-and particularly when they are trying to decide whether to become interdependent with each other-they should be motivated to evaluate each other in an unbiased way.

Yet, when early relationship processes and important relationship decisions are directly examined, people appear to show substantial pro-relationship biases even in those contexts. People evaluate targets more positively when they are presented as potential dating partners compared to when they are not (Berscheid et al., 1976). People agree to dates with people who fall below their stated dating standards when they have met only once (Eastwick et al., 2011) or even not at all (Joel et al., 2014). In the context of brand-new dating relationships, before important commitments have been made, people shift their goals and ideals to match the partners they have (Gere \& Impett, 2017; Gerlach et al., 2019; Fletcher et al., 2000). These findings suggest that people are highly motivated to see new partners or even potential partners in a positive light. Thus, models of relationship evaluation may fit the data better to the extent that they accommodate pro-relationship biases from the very start of the relationship, before interdependence or commitment have had a chance to develop. Even brand-new dating opportunities are graded on a curve. 
Table 1: A Summary of Evidence for the Progression Bias

\section{Relationship Initiation}

\section{Behavioral Evidence}

People pursue potential partners who do not meet their stated dating standards

People "yes" a relatively large portion of options in speed-dating contexts, including those who do not conform to stated preferences

People evaluate brand-new potential romantic partners in a positively biased way

Relationships that begin as casual sexual encounters frequently transition into committed relationships

When presented with many dating options, people take a satisficing approach of rejecting the worst options rather than selecting the best options

\section{Potential Mechanisms}

Motivational Fear of being single leads to less selective mate decisions

Motivational Missing a romantic opportunity is perceived to be more regrettable than being rejected

Cognitive Humans are poorly equipped to exhaustively evaluate a large number of mating options

Evolutionary In simulation studies, agents with less selective mate strategies are more successful and become more populous

\section{Citations}

Eastwick et al. 2011; Slotter \& Gardner, 2012; Joel et al. 2014 Kurzban \& Weeden, 2007; Joel et al. 2017

Berscheid et al. 1976

Machia et al., 2020; Owen \& Fincham, 2012; Timmermans \& Courtois, 2018

Jonason et al., 2015; Long \& Campbell, 2015

Spielmann et al., 2013

Joel et al., 2019

Lenton et al. 2008; 2010; Wu \& Chiou, 2009

Neth et al. 2011; Todd, 1997 
Conley \& Collins, 2002; Hertel et al., 2007; Greitemeyer, 2009; Morris et al., 2007

\section{Relationship Advancement}

\section{Behavioral Evidence}

In samples of young, single individuals, a non-trivial percentage $(\sim 30 \%)$ tend to fall in love within a few months

Even relationships labeled as casual or short-term tend to follow investment trajectories that are indistinguishable from long-term relationships

People come to view new romantic partners as attachment figures within the first few months of dating

People in brand new relationships adjust their dating standards and goals to match their new dating partners

\section{Potential Mechanisms}

Motivational Sexual desire motivates investment behaviors

Motivational Investment from one partner motivates commitment from the other, even when the relationship is low quality

Biological Romantic love is associated with reward systems in humans (e.g., heightened activation of the VTA)

\section{Citations}

Aron et al., 1995; Gerlach et al., 2017

Eastwick et al., 2018

Heffernan et al., 2012; Fagundes \& Schindler, 2012

Gerlach et al., 2017; Fletcher et al., 2000; Gere \& Impett, 2017

Birnbaum et al., 2017; Gillath et al., 2008

Joel et al., 2013

Acevedo \& Aron, 2014; Burkett \& Young, 2012; Aron et al., 2005; Bartels \& Zeki, 2000; 2004; Xu et al., 2011; Acevedo et al., 2012 
Biological

Pair-bonding is also linked to reward systems in other animals such as prairie voles

Cognitive The decision to move in together is often made with little conscious deliberation

\section{Relationship Maintenance}

\section{Behavioral Evidence}

People show a preference for existing partners over more attractive partners even in hypothetical contexts

Many struggle to leave even unhealthy or abusive relationships

Dissolved partnerships frequently reconcile

\section{Potential Mechanisms}

Motivational Relationship investments create barriers to dissolution

Motivational Concern for the partner's feelings creates barriers to dissolution

Motivational Fear of being single creates barriers to dissolution

Motivational Break recovery is as difficult for rejectors as it is for rejectees

Biological Endogenous opioids play a role in relationship maintenance

Biological Even temporary separation from a romantic partner is associated with physiological dysregulation
Burkett et al., 2011; Johnson \& Young, 2015; Aragona, et al., 2006

Lindsay, 2000; Manning \&

Smock, 2005; Sassler, 2004

Gunaydin et al., 2018

Arriaga, 2002; Arriaga et al., 2013; Rusbult \& Martz, 1995; Dailey, Rossetto et al., 2009;

Dailey, Pfiester, et al., 2009

Rusbult et al., 1998; Stanley et al., 2006

Perilloux \& Buss, 2008; Joel et al., 2018

Spielmann et al., 2013

Sbarra, 2006

Inagaki, 2016; 2018; Panksepp et al., 1980; Panksepp, 1998; Tchalova \& MacDonald, 2020

Diamond et al., 2008 
Cognitive

Breakup decisions tend to be deliberative and effortful
Battaglia et al., 1998;

Vanderdrift et al., 2009; Joel et al., 2017 


\section{Countervailing Evidence}

Thus far, we have focused on evidence in support of the idea that people tend to undiscerningly select partners, rapidly invest in new connections, and struggle to end unsatisfying partnerships. A summary of such evidence is presented in Table 1 . However, it is certainly not the case that all fledging relationships progress into serious partnerships, or that everyone who wants a romantic partner obtains one. In the previous section, we presented several base rates suggesting that relationship formation is a common experience. Yet, it is not ubiquitous. In the study in which $15 \%$ of friends-with-benefits relationships transitioned into dating relationships, it is also true that $85 \%$ did not (Machia et al., 2020). In two studies that have tracked single individuals over several months, approximately one third entered relationships in that time, which means that two thirds did not (Campbell et al., 2016; Gerlach et al., 2019).

Below, we consider available contrasting evidence to the progression bias. What limitations, boundary conditions, or counteracting mechanisms might exist? We explore whether this bias may be weaker for certain individuals than others, including a) those

with strong fears of rejection, b) highly attractive individuals, c) women, d) avoidantly attached individuals, and e) less prosocial individuals.

\section{How Strongly Do Fears of Rejection Inhibit Relationship Initiation?}

Rejection is an acutely painful experience that humans are highly motivated to avoid (e.g., Eisenberger et al., 2003; MacDonald \& Leary, 2005; Williams et al., 2000). Thus, a desire for romantic connection must be balanced against the competing goal of minimizing the pain of rejection (Clark \& Beck, 2011; Murray et al., 2006). Such fears of rejection may 
inhibit relationship initiation. For example, among a sample of 291 undergraduate participants, $76 \%$ of participants reported that their fear of rejection had posed a significant obstacle to pursuing a romantic relationship at least once, and 54\% reported that fear of rejection had completely prevented them from pursuing a romantic relationship at least once in their lives (Vorauer \& Ratner, 1996). Fear of rejection may also inhibit the development of a relationship in part by inhibiting discussions about the course the relationship is taking. In one line of research, the state of friendships and romantic relationships was the most commonly mentioned taboo topic in those relationships, particularly among participants reporting on potential romantic relationships (Baxter \& Wilmot, 1985). Many participants worried that discussing the state of the relationship would damage it, or that their (potential) partner would feel differently about the relationship than they did. Such concerns may lead people to try to acquire information about the state of their relationships through indirect means ("secret tests"; Baxter \& Wilmot, 1984).

Even when fears of rejection do not outright prevent people from pursuing romantic partners, those fears may at least make successful pursuit less likely. Individuals with chronically heightened fears of rejection, such as those with high attachment anxiety or low self-esteem, have been shown to engage in a variety of behaviors that may reduce their odds of romantic success. For example, anxiously attached individuals may make muted romantic overtures relative to secures, while also overestimating how direct and welldetected their overtures are (Vorauer et al., 2003). Individuals with lower self-esteem have been shown to underestimate how accepted they are by potential dating partners (Cameron et al., 2010). Both anxiously attached and low self-esteem individuals may also 
show signs of social disengagement in dating situations that make their own acceptance less likely (McClure \& Lydon, 2014; Stinson et al., 2015). For example, in two experiments, participants were asked to record a video of themselves (Stinson et al., 2015). When participants believed that the video would be shown to an opposite-sex participant who they may get a chance to meet (i.e., there were opportunities for romantic connection and rejection), individuals with low self-esteem were particularly likely to engage in cold, protective behaviors that ironically made them appear less likeable to observers.

Despite this evidence of the potency of rejection fears, we posit that competing, prorelationship motivations commonly override such fears in favor of pro-relationship decisions. Humans have an intrinsic need for close, enduring social connections (the fundamental need to belong; Baumeister \& Leary, 1995). Rejection is painful precisely because it thwarts this need to belong (MacDonald \& Leary, 2005). Yet, failing to establish close social ties threatens that very same need. Decisions that help to form and maintain close relationships can be driven not just by approach-based motivations (e.g., a desire for intimacy), but avoidance-based ones as well (e.g., fears around loneliness). Such competing motivations may be particularly strong specifically among the individuals who fear rejection the most. For example, several studies suggest that anxiously attached individuals are particularly concerned about missing romantic opportunities (Joel, Plaks, \& MacDonald, 2019) and winding up without a partner (Spielmann et al., 2013), which may lead them to be even less selective than secure individuals. Individuals higher in attachment anxiety have been shown to say "yes" to more potential matches in the context of speed-dating (McClure et al., 2010), and to be particularly likely to maintain commitment to romantic partners who are not meeting their needs in the context of long-term relationships (Slotter 
\& Finkel, 2009). One study further suggests that anxiously attached individuals have particular strategies for conveying themselves positively to potential dating partners, such as being more talkative and engaging in more humor (although they are simultaneously seen as being more neurotic; Brumbaugh \& Fraley, 2010). Overall, we posit that although insecure individuals have heightened fears of rejection, the inhibiting effect of those fears may be mitigated by their simultaneously heightened desire for a long-term partner and associated compensatory dating strategies.

Methodological limitations constrain the conclusions we can presently draw about how rejection concerns shape relationship initiation. On one hand, most studies examining the impact of rejection fears on relationship initiation have employed methods such as hypothetical vignettes (Joel et al., 2019; Vorauer \& Ratner, 1996), or videos recorded for hypothetical partners (Brumbaugh \& Fraley, 2010; Stinson et al., 2015), which do not directly capture relationship initiation decisions or outcomes. On the other hand, studies that have captured real relationship initiation have generally employed speed-dating methods (e.g., Joel et al., 2017; McClure et al., 2010). In standard speed-dating paradigms, participants are not made aware of each other's pursuit choices unless their romantic interest is reciprocal, greatly minimizing the emotional risks associated with expressing romantic interest. Thus, speed-dating studies may fail to capture the motivational impact of rejection concerns. Another methodological consideration is that research has largely focused on the romantic pursuit of strangers, yet many romantic relationships begin as friendships or as acquaintances (Eastwick et al., 2018; Kaestle \& Halpern, 2005). It seems plausible that in some ways rejection fears would be stronger when the romantic target is known, as being rejected by that person could have negative implications for the existing 
relationship as well as for one's broader social circle. At the same time, this slower way of getting to know potential romantic partners may be useful for reducing uncertainty regarding the potential partner's level of interest, thus reducing rejection fears. Overall, more research is needed that captures real relationship initiation, particularly in naturalistic settings, to better understand how people weigh their desire for a romantic relationship against rejection concerns.

\section{Does Physical Attractiveness Afford Greater Choosiness?}

Thus far, we have argued that people frequently bend or lower their romantic standards in the interests of securing a romantic partner. However, it is almost certainly not the case that people have no degree of choosiness when selecting a mate. Physical attractiveness is a particularly concrete dating criterion that appears to shape not only mate preferences (particularly for men; e.g., Buss, 1989; Feingold, 1990; Li et al., 2002; Li \& Kenrick, 2006), but also real mate decisions (e.g., Byrne et al., 1970; Eastwick \& Finkel, 2008; Joel et al., 2017; Kurzban \& Weeden, 2005; Li et al., 2013; Luo \& Zhang, 2009; Taylor et al., 2011; Walster et al., 1966). For example, in a speed-dating study consisting of 10,526 participants, romantic choices were most strongly predicted by the physical characteristics of the romantic target, such as facial attractiveness, height (for male targets), and weight (for female targets; Kurzban \& Weeden, 2005). In another speed-dating study (combined N = 350), machine learning analyses identified perceptions of own physical attractiveness and mate value as two of the strongest predictors of being desired by other participants (Joel et al., 2017).

These findings point to physical attractiveness as a potential moderator of the progression bias. If individuals who are more physically attractive have higher objective 
mate value-meaning that they can attract a broader range of potential partners-then those individuals should be able to afford greater selectivity when making their own dating choices. Some lab studies have evidence for this idea. More physically attractive individuals, as rated by observers, have been shown to report higher mating standards (Buss \& Shackelford, 2008), and to perceive individuals in photographs as being less physically attractive and less likely to reject them romantically (Montoya, 2008). However, studies of real dating behavior have provided mixed support for the hypothesis (Lee et al., 2008; Taylor et al., 2011; Spielmann et al., 2020). For example, one study examined the initiation behaviors of 966 individuals on a dating website (Taylor et al., 2011). Although more physically attractive participants did receive more interest overall, participants' own physical attractiveness was not correlated with the attractiveness of the individuals who they chose to contact. Another study, consisting of nearly 450,000 observations scraped from HotorNot.com, found that physically attractive people were more selective in their choice of dating partners (Lee et al., 2008). For every 1-unit decrease in attractiveness on a 10-point scale, participants were $25 \%$ more likely to say "yes" to any given potential date. However, this same study showed a null association between others' ratings of own attractiveness and own ratings of others' attractiveness, suggesting that evaluations of others' attractiveness are not shaped by one's own mate value.

As with research on rejection, research on how attractiveness shapes mate selection processes has focused almost exclusively on the context of strangers, often based on profile photos (e.g., in the case of online dating research) or brief interactions (e.g., speed-dating research). However, people's agreement about which individuals are attractive may diverge over time as they get to know potential partners. In one study, 129 students were 
asked to rate their opposite-sex classmates on a variety of mate-value-relevant traits at the beginning versus at the end of the semester (Eastwick \& Hunt, 2014). Even at the beginning of the semester, relatively more of the variance in mate value ratings were explained by the perceiver (some individuals generally saw others as attractive), or by the relationship (some pairs of individuals saw each other as uniquely attractive), rather than by the target (agreement across classmates on which individuals were attractive). By the end of the semester, the amount of variance shared across targets had significantly decreased, whereas relationship-specific variance had increased. In other words, as classmates came to know each other, their views of each other were increasingly shaped by the unique interactions that they shared. Thus, in the context of acquaintances or friends in which many romantic relationships form, objective qualities such as physical attractiveness may play a less prominent role than they do in the context of strangers (Hunt et al., 2015).

\section{Are Women Choosier Than Men?}

Evolutionary perspectives on psychology suggest that the progression bias should be stronger on average for men than women. Parental investment theory posits that within a given species, the sex that is required to invest relatively more in the production of offspring (usually female) is more selective in their choice of mates, whereas the sex that is required to invest less (usually male) competes intrasexually for access to mates (Trivers, 1972). This sex difference is present in most mammals, including humans: the minimum investment required for men to reproduce is insemination, whereas women must invest, at minimum, nine months in a single pregnancy. These biological differences are theorized to have generated different adaptive mating problems for men and women, resulting in sex differences in mating strategies (Buss \& Schmitt, 1993). Particularly in the short-term 
mating context, women are theorized to be more selective than men about their mates, and to be less willing to lower their romantic standards in exchange for securing a mate. These hypotheses are also consistent with heteronormative social scripts, whereby men are socialized to take on the role of the pursuers of sex, whereas women are the gatekeepers (e.g., Wiederman, 2005).

Considerable evidence supports women's greater selectivity during the initial dating stages. For example, in the context of speed-dating, men tend to express greater interest in their potential partners than women (e.g., Kurzban \& Weeden, 2005; Spielmann et al., 2020; Todd et al., 2007; although see Asendorpf, Penke, \& Back, 2011; Finkel \& Eastwick, 2009 for potential moderators). Men also initiate more conversations in the context of online dating (e.g., Kreager et al., 2014; Sharabi \& Dykstra-De Vette, 2019; Timmermans \& Courtois, 2018). Women receive more matches on dating apps such as Tinder (Timmermans \& Courtois, 2018), and are more likely to be romantically pursued by someone in whom they are not interested (Bohns \& DeVincent, 2019). Similar findings have been obtained in lab settings. In one experiment, 50 heterosexual men and 50 women were randomly paired for a 10-minute conversation (Fletcher et al., 2014). Women reported significantly higher minimum dating standards than men prior to the interaction, and expressed lower romantic interest after the interaction. In total, $72 \%$ of men agreed to make further contact with their interaction partners, compared to only $36 \%$ of women, resulting in 13 matches ( $26 \%$ of possible matches).

These findings suggest that there are robust sex differences in the initial choice to pursue a new dating partner, with men initiating more frequently and being open to a broader range of partners than women. However, these findings have largely been 
obtained in the context of partners who have either never met (e.g., Kreager et al., 2014; Sharabi \& Dykstra-De Vette, 2019), or who have met only briefly (e.g., Fletcher et al., 2014; Kurzban \& Weeden, 2005; Spielmann et al., 2020; Todd et al., 2007). Less research has examined whether such sex differences persist once a relationship has formed. Some studies have suggested that men may fall in love more quickly (Harrison \& Shortall, 2011) and declare their love for their partners earlier on in the relationship (Ackerman, Griskevicius, \& Li, 2011). On the other hand, a well-powered cross-sectional study found no gender differences in the tendency to rely on romantic partners as attachment figures across different relationship lengths (Heffernan et al., 2012), suggesting that men and women may become attached to new partners at similar rates. Similarly, across several studies in which people retrospectively charted their romantic interest trajectories, the development of both short- and long-term relationships appeared highly similar for both men and women (Eastwick et al., 2019). Consistent with the literature summarized above, men reported experiencing greater romantic interest at the very beginning of the relationship, but that difference quickly diminished as the relationship progressed. Overall, although women may be choosier than men when initially deciding whether to date a person, there is little evidence to suggest that they would be any more or less motivated to move the relationship forward once it has begun.

\section{Do Avoidant Individuals Show A Progression Bias?}

A key mechanism that motivates people to pursue and persist with romantic partnerships is the social rewards that accompany them. However, some individuals are not strongly engaged with the social rewards associated with romantic relationships. Attachment avoidance-one of the two dimensions of individual differences in attachment 
style (Bowlby, 1969; Hazan \& Shaver, 1987; Fraley \& Waller, 1998)—captures discomfort with intimacy and closeness, and a preference for relying on the self rather than on close others (Mikulincer \& Shaver, 2007). Consistent with this definition, avoidantly attached individuals perceive both current and potential dating partners as being less socially rewarding (Gere et al., 2013; Spielmann, Maxwell, MacDonald, \& Baratta, 2013), particularly when there is potential for intimacy. They tend to avoid intimacy-building activities such as self-disclosure (e.g., Tan, Overall, \& Taylor, 2012) and find sex to be less enjoyable (e.g., Tracy, Shaver, Albino, \& Cooper, 2003) and more aversive (Birnbaum, Reis, Mikulincer, \& Gillath, 2006). On a more cognitive level, avoidantly attached individuals hold more pessimistic scripts for their relationships. Whereas people generally tend to make overly optimistic future-oriented judgments about their relationships (e.g., Baker \& Emery, 1993; T. K. MacDonald \& Ross, 1999), some evidence suggests that avoidantly attached individuals expect their relationships to fail (Birnie, McClure, Lydon, \& Holmberg, 2009). Overall, avoidantly attached individuals tend to see romantic relationships as holding less potential for reward, both currently and in the future.

If reward is a key mechanism that fuels the progression bias, then avoidantly attached individuals may show a weaker progression bias, meaning that they may be less prone to pursuing and persisting with romantic relationships compared to those lower in avoidance. Consistent with this idea, avoidant individuals have been shown to report lower commitment to their romantic partners (e.g., Pistole, Clark, \& Tubbs, 1995) and shorterrelationships (Hazan \& Shaver, 1987). Avoidantly attached individuals may also be more likely to experience long-term singlehood (Chopik, Edelstein, \& Fraley, 2013; Ringstad \& Pepping, 2016). In one longitudinal study ( $\mathrm{N}=90)$, individuals with higher attachment 
avoidance were less likely to enter a committed romantic relationship over a span of eight months (Schindler, Fagundes, \& Murdock, 2010). Further, more avoidantly attached individuals in relationships expect relationship loss to hurt less (Spielmann et al., 2013) and report fewer grief symptoms in response to the death of a spouse (LeRoy et al., 2020). Overall, there is considerable evidence that romantic relationships do not hold the same draw for individuals with higher attachment avoidance relative to those lower in avoidance, nor the same costs to exiting relationships, such that the progression bias should be attenuated for them.

\section{Are Less Prosocial People Better at Rejecting Undesired Partners?}

Another potentially relevant moderator of the progression bias is a person's degree of prosocial motivation. Even when own romantic interest is low, people are often reluctant to hurt another person's feelings by expressing that lack of interest (Bohns \& DeVincent, 2019; Baumeister, Wotman, \& Stillwell, 1993). These other-oriented concerns may dissuade people from rejecting unsuitable partners, or from ending low-quality romantic relationships. For example, in one study, people were significantly more willing to agree to dates with unattractive or incompatible suitors in reality than they predicted they would be hypothetically, in part because of people's heightened concerns about hurting their potential partner's feelings in the real conditions (Joel et al., 2014). In a sample of people who had recently experienced a breakup, and compared to those who had been broken up with, the participants who had chosen to end the relationship reported feeling guiltier and more concerned about being perceived as cruel (Perilloux \& Buss, 2008). In a vignette study, participants chose to remain with an existing partner rather than take the opportunity to date a more attractive partner in part because they were concerned about 
hurting the existing partner's feelings (Gunaydin et al., 2018). In a recent longitudinal study, 1281 participants in dating relationships were tracked over a 10-week period (Joel et al., 2018). People who perceived their partners to be more committed to the relationship were less likely to initiate a breakup over the course of the study, even if their selfinterested motivations to maintain the relationship (own satisfaction, investment, commitment, etc.) were low. A preregistered replication uncovered similar results.

Prosociality is normative, such that most people are intrinsically motivated to consider the needs and feelings of other individuals (e.g., Rand, Greene, \& Nowak, 2012; Yamagishi, Li, Takagishi, Matsumoto, \& Kiyonari, 2014), especially romantic partners (e.g., Collins \& Ford, 2010; Rusbult \& Van Lange, 2003). However, people also vary in the strength of their prosocial motivation, as captured by personality traits such as empathy (Batson et al., 1988; Davis, 1996), agreeableness (Graziano \& Eisenberg, 1997; Graziano, Habashi, Sheese, \& Tobin, 2007), and communal orientation (Clark \& Mills, 1993). People with strong prosocial tendencies may show a particularly strong progression bias. For example, in the Joel et al. (2018) study, the associations between perceived partner commitment and breakup decisions were largely moderated by communal strength, such that people who reported strong concern for their partner's welfare (Clark \& Mills, 1993; Mills et al., 2004) were particularly unlikely to break up with a highly dependent partner. These findings point to the possibility that individuals with traits associated with a lack of prosocial motivation, such as the dark triad traits (Machiavellianism, narcissism, and psychopathy; Paulhus \& Williams, 2002), may show a particularly weak progression bias. That is, if prosocial concerns are a key mechanism that pushes people toward advancing and maintaining even low-quality relationships, then people who lack prosocial concerns 
may be particularly good at rejecting such partnerships. Dark Triad traits in general have been linked to a preference for short-term relationships rather than those involving more commitment (Jonason et al., 2009; 2012). Narcissism in particular is associated with lower commitment to romantic partners (e.g., Campbell \& Foster, 2002). The idea that this may in part arise from the less communal nature of narcissists is supported by the finding that activating communal norms can strengthen narcissists' commitment (Finkel et al., 2009). Further, narcissists appear to be particularly less committed to unsatisfying relationships as the link between satisfaction and commitment is notably strong for them (Foster, 2008). In sum, individuals who tend to be less concerned about the wellbeing of others may be less prone to making pro-relationship choices, particularly in the context of partnerships that are not meeting their needs.

\section{Future Directions}

This review of the existing evidence reveals several empirical gaps to be filled by future research. Below, we outline several outstanding questions about the progression bias, in each case highlighting methodological innovations that we believe are needed in order to obtain satisfying answers to these questions.

\section{What Mechanisms Underlie the Progression Bias? A Need for Integrative Approaches}

What specific mechanisms might drive the progression bias? There is direct evidence for some of the mechanisms put forth in this paper, such as infatuation (e.g., Aron et al., 2005; Birnbaum et al., 2017; Eastwick \& Finkel, 2008; Gillath et al. 2008), fears around singlehood (Spielmann et al., 2013), and prosocial concerns (Bohns \& DeVincent, 2019; Joel et al., 2018). There is also suggestive evidence of the role of other potential mechanisms. For example, people in committed relationships tend to make overly 
optimistic judgments about a relationship's future (e.g., T. K. MacDonald \& Ross, 1999; Joel, Spielmann, \& MacDonald, 2017). In one survey of newlyweds, participants correctly estimated the divorce rate with a median response of $50 \%$, yet they estimated their own likelihood of experiencing a divorce at a median of 0\% (Baker \& Emery, 1993). Future research should examine whether people make similarly optimistic judgments about brand new dating partners or even potential dating partners, and if so, whether those judgments may help motivate people to invest and commit to new partners in the first place.

One challenge in identifying mechanisms for the progression bias is that romantic relationships can be leveraged as a tool to meet a wide variety of needs, including evolved desires for intimacy (Baumeister \& Leary, 1995) and sex (Park, Impett, \& MacDonald, in press), social pressures for status and conformity (Day et al., 2011), practical considerations such as access to material necessities (Eagly, Eastwick, \& JohannesenSchmidt, 2009), and psychological needs such as self-esteem (Leary \& Baumeister, 2005), meaning (Florian \& Mikulincer, 2002), and reality testing (Rossignac-Milon, Bolger, Zee, Boothby, \& Higgins, 2021). Given that each of these (and likely more) can act individually or in concert to lead individuals to be prone to make decisions that promote rather than curtail relationships, future research will need comprehensive approaches that examine the progression bias as multiply motivated.

One such approach might involve Latent Profile Analysis (e.g., Collins \& Lanza, 2009) to identify clusters of motives and their connections to progression versus selectivity. Some clusters of motives may be satisfied by virtually any romantic partner and thus may be particularly tied to a tendency to move relationships forward. For example, people who are particularly driven by fears around singlehood, social pressure to enter a 
relationship, or a desire for the broader social benefits of couplehood may be particularly susceptible to the progression bias. Some clusters of motives may be satisfied by a broad but not unlimited range of partners. For example, psychological needs such as intimacy, self-esteem, and meaning may be satisfied by any romantic relationship that meets a minimum threshold of quality. Yet other motives may have concrete boundary conditions that can predictably curtail the likelihood of relationships moving forward. For example, people who are looking for a relationship to meet their material needs may require a partner with a minimum level of wealth. Further, this process of identifying relationship motivation profiles would need to be sensitive to life and relationship stages. Presumably, the weights of particular factors that push relationships forward would change both as relationships change (e.g., before versus after having a child) and as individuals age (e.g., as one nears retirement).

\section{How Domain-Specific is the Progression Bias? Considering Other Relationship Types}

Thus far, we have focused on evidence for the progression bias specifically in the romantic domain. However, some studies have captured similar effects in non-romantic contexts. For example, several classic lab experiments have found that people report greater liking for same-sex targets when they believe that they will have to interact with them (Darley \& Berscheid, 1967; Tyler \& Sears, 1977). The efficacy of the fast friends procedure-in which strangers are asked to make increasingly personal disclosures to each other-demonstrates how readily platonic closeness can be generated in the lab (Aron et al., 1997). Another classic social psychology maxim, sometimes referred to as the proximity effect, holds that friendship formation is determined in large part by mere geographic proximity (e.g., Festinger et al., 1950; Segal, 1974). Such studies point to the 
possibility that people's tendency to unselectively and intuitively form close social bonds may not be unique to the romantic context.

Romantic relationships have arguably received more empirical attention than any other kind of close relationship, consistent with the unique value that Western society assigns to romantic bonds (DePaulo \& Morris, 2005). Thus, we know relatively less about the development of platonic relationships such as friendships. However, theories such as the need to belong (Baumeister \& Leary, 1995), social baseline theory (Beckes \& Coan, 2011), and attachment theory (Bowlby, 1969) make clear that humans are embedded in broader social networks and rely on a wide variety of relationships beyond their romantic partners to meet important needs. Future work could consider exploring how people choose to pursue, invest in, other kinds of bonds (friendships, for example), and directly comparing those processes to those observed in the context of romantic relationships. Some of the mechanisms we have put forth for the progression bias are unique romantic in nature, and thus seem unlikely to generalize to other close relationship contexts (e.g., sexual desire, infatuation, societal pressure to marry). Other mechanisms, such as those concerning attachment systems and broader belongingness needs, should be relevant to the formation of close relationships more broadly.

\section{What Determines Which Relationships Develop and Which Do Not? A Need for}

\section{Longitudinal Approaches}

The existence of a progression bias does not mean that all relationships progress. How are the many motivations to pursue versus avoid potential partners weighted to determine which partnerships develop and which fizzle out? One challenge here is that the methods chosen to examine the individual contributions of factors inhibiting versus 
impelling relationships are often chosen more for research convenience than for the validity of the approach (e.g., Flake, Pek, \& Hehman, 2017). For example, the vast majority of partner choice research has focused on hypothetical dating profiles and self-reported partner preferences in which affective forecasting errors regarding both the power of both rewards and rejection risk may be common (e.g., Nordgren, Banas, \& MacDonald, 2011). A relatively small set of studies has examined mate choice in response to real dating options (e.g., Eastwick et al., 2011; Fletcher et al., 2014; Kurzban \& Weeden, 2007; Joel et al., 2014; 2017; Taylor et al., 2011), although most of these involve contexts in which both indicating interest in and rejecting a partner are done as a choice in an anonymous format rather than a direct approach (e.g., speed dating). An even smaller set of studies has tracked new relationships over time as they first develop, an approach that might best capture realworld dynamics (e.g., Gere \& Impett, 2017; Gerlach et al., 2019; Fletcher et al., 2000; Machia et al., 2020). As a result, we know a lot about what people say they want in a romantic partner, a little about what leads to real romantic interest at a distance, and very little about which fledging partnerships tend to develop into long-term ones.

Early relationship investment decisions may be a particularly relevant, yet largely untested determinant of which fledging relationships persist or desist. In the early stages of a relationship, people make a series of relatively small decisions-such as whether to agree to take the new partner on a weekend trip, introduce them to a friend group, or make future plans together-that collectively amount to feeling invested in that relationship. Investment, in turn, is one of the strongest predictors of commitment and stability (e.g., Rusbult, 1980; 1983). Yet, we know very little about the processes through which people make these decisions and thereby come to feel invested in new partnerships. The 
progression bias offers testable hypotheses about how these investment decisions are likely to unfold. Opportunities to invest (e.g., spending more time together, planning a trip together) should generally be taken easily and without much deliberation, whereas forgoing opportunities to invest should be more difficult and distressing. Data on the decision to move in with a partner-one of the only concrete investments that has been studied in depth—are consistent with these predictions (e.g., Lindsay, 2000; Manning \& Smock, 2005; Sassler, 2004). Overall, more research is needed tracking real relationships over time to understand how fledgling connections do or do not progress into long-term partnerships.

\section{What are the Practical Implications of the Progression Bias? A Need for Diverse Perspectives and Sampling}

Another important remaining question is whether the progression bias is a force that promotes satisfaction and/or stability in relationships or instead traps people into less satisfying relationships. In the same way that other intuitive impulses can conflict with long-term goals, people may sometimes struggle to resist the urge to pursue romantic opportunities and invest in new relationships even when important incompatibilities are present. In this way, the progression bias may help to promote the development of lowquality relationships, with downstream negative outcomes for health and wellbeing. Alternatively, the progression bias may help smooth over rough patches on the way to building deep, long-term connections. People's tendencies to pursue and build relationships despite a partner's flaws may be common or even necessary steps along the road to a functional partnership. 
Cross-cultural research may offer particular insight into this question, as different cultures vary in norms that allow for more versus less relational choice as well as norms that permit versus restrain the decision to leave established relationships (Heu, Hanson, \& Van Zomeren, 2021). Are individuals more connected in their relationships in contexts that make relationships easier to move into and harder to move out of? Heu et al. (2021) perhaps not surprisingly found that countries in which it was easier to start relationships featured lower levels of loneliness, but also found evidence (albeit less robust) that countries in which it was less permissible to leave relationships also featured lower loneliness. These data tentatively suggest the possibility that a progression bias may promote relationship connection. Having said that, future research on the progression bias should be attentive to multiple outcomes beyond relationship satisfaction/stability, including power, conflict/abuse, and feelings of autonomy.

In general, the current review reveals a clear need for more cross-cultural research on partner choice and relationship development. Research from North America and Western Europe dominates relationship science, and yet these areas are oddly unique in the world context with their relatively minimal role for family in partner selection (Apostolou, 2007; Buunk et al., 2010; Walker et al., 2011). Indeed, cultures in which arranged marriage of various forms is a regular practice (e.g., Allendorf \& Ghimire, 2013; Desai \& Andrist, 2010; Ghimire et al., 2006; Hamid et al., 2011; Imamoğlu et al., 2019) arguably embed notions of a progression bias into that practice. Many such cultures hold that incorporating the wisdom of the elders into partner selection contributes to a solid relationship foundation that may begin with relatively low levels of love, but that will ultimately grow into a stable long-term relationship that is sustainably caring and warm 
(Xiaohe \& Whyte, 1990). Of course, as with Western ideals of self-choice, these family choice models in many cases do not live up to their ideals, but there is evidence in the context of India that arranged marriage can be as, if not more, satisfying than love matches (e.g., Mir, Wani, \& Sankar, 2016; Raina \& Maity, 2018; Yelsma \& Athappilly, 1988). Crosscultural work that attends to the family as another source of motivation to move relationships forward (MacDonald \& Jessica, 2006; MacDonald, Marshall, Gere, Shimotomai, \& July, 2012) will be important in order to understand the operation of the progression bias in the bulk of the world's relationship contexts.

Even within Western cultures, there is a pressing need to incorporate more diverse perspectives and experiences into our relationship models. The dating landscape does not hold equal opportunity for everyone: some individuals have greater or fewer dating options because they belong to groups that enjoy privilege or face stigma on the dating market. For example, considerable research suggests that whiteness is privileged in the context of online dating (at least in white-majority cultures), with white targets receiving greater romantic interest than targets from other racial groups (e.g., Chopik \& Johnson, 2021; OKCupid, 2014; Ranzini \& Rosenbaum, 2020). Racial and gender stereotypes intersect in ways that may lead to particularly high levels of prejudice against Black women and Asian men (e.g., Robnett \& Feliciano, 2011), consistent with North American stereotypes that link Black and Asian identities with masculinity and femininity, respectively (Galinsky et al., 2013; Schug et al., 2015). Disabilities are another potential source of dating stigma (Miller et al., 2009). One group that faces particularly strong barriers to finding romantic partners is transgender individuals. In one study of 958 participants, $87.5 \%$ indicated that they would not consider dating a trans person, including 
97\% of the cisgender heterosexual participants sampled (Blair \& Hoskin, 2019). Some groups also have access to smaller dating pools due to structural inequalities. For example, in the United States, Black women in particular face demographic shortages in available dating partners (e.g., Lichter et al., 2019), at least partially due to high rates of incarceration among Black men (e.g., Charles \& Luoh, 2010).

Unfortunately, these same groups that face barriers on the dating market tend to also be quite underrepresented in the context of relationship science, which has overwhelmingly focused on the experiences of white, cis, heterosexual, assumed-to-be nondisabled individuals from the United States (Williamson, 2021). Most of the research reviewed in the current paper is subject to these sampling limitations. As such, it is currently unknown how the progression bias might operate in more diverse contexts or what its downstream implications might be for those groups. On one hand, conditions of high partner scarcity might strengthen the progression bias. In the same way that perceiving a lower quality of alternatives predicts higher commitment to existing relationships (Rusbult, 1980; 1983), a dearth of available dating partners may motivate people to capitalize on the dating opportunities that do arise. On the other hand, if people generally take a satisficing approach to mate selection (i.e., the goal is to wind up with a minimally suitable partner), then careful adherence to one's dating standards may be particularly important precisely when the risk of winding up with an unsuitable partner is high. Members of marginalized groups may also have unique dealbreakers to consider in the context of dating, such as concerns around racism (Luke \& Oser, 2015) or fetishization (e.g., Anzani et al., 2021), that have not been incorporated into existing models of relationship standards. Overall, gaining a satisfying understanding of the mechanisms and 
broader consequences of the progression bias (and other relationship models) will require researchers to consider broad swaths of the human population that have traditionally been neglected.

\section{Conclusions}

Growing evidence suggests that people have a bias for decisions that move romantic relationships towards commitment rather than dissolution. Single individuals appear to be open to a broad range of dating partners (Kurzban \& Weeden, 2007; Joel et al., 2017) and motivated to see potential dating partners in a positive light (Berscheid et al., 1976) to the extent that they will overlook potential flaws and incompatibilities (Eastwick et al., 2011; Joel et al., 2014; Slotter \& Gardner, 2012). People in new dating relationships tend to become rapidly attached to their new dating partners (Heffernan et al., 2012; Fagundes \& Schindler, 2012), and adjust their dating standards to match their partners (Campbell et al., 2015; Gerlach et al., 2019; Gere \& Impett, 2017). The decision to move in with a romantic partner is often made with little conscious deliberation (Lindsay, 2000; Manning \& Smock, 2005; Sassler, 2004; Stanley et al., 2006). Such investments, in turn, serve as barriers to relationship dissolution (Le \& Agnew, 2003; Rusbult, 1980; 1983; Tran et al., 2019). The decision to end a relationship tends to be highly effortful and difficult (Dailey et al., 2009; Joel et al., 2017; VanderDrift et al., 2009), even when the relationship is unhealthy or even abusive (Arriaga, 2002; Arriaga, 2013; Rusbult \& Martz, 1995).

Why do people show this progression bias? Existing literature points to both potentially evolved biological mechanisms (e.g., reward-based processes; Aron et al., 2005; Acevedo et al., 2012; Acevedo \& Aron, 2014; Diamond, 2014; Xu et al., 2011) as well as cultural reinforcement mechanisms (e.g., benefits associated with coupledom; Day et al., 
2011; DePaulo \& Morris, 2005; familial influence; Apostolou, 2007). Future work should consider the theoretical implications that this phenomenon has for our understanding of romantic pursuit (e.g., Bredow et al., 2008), interdependence (e.g., Murray et al., 2006), and partner evaluation (e.g., Fletcher et al., 1999). To better understand the mechanistic underpinnings of the progression bias, future work should consider studying multiplepotential mechanisms in tandem, and consider how they may be weighted differently for different individuals. There is an empirical need for more longitudinal work that tracks real dating relationships over time as they develop. We should consider which aspects of the progression bias may be generalizable to other kinds of relationships (e.g., friendships), versus unique to the romantic domain. Finally, to improve our understanding of the progression bias and of relational development more broadly, there is a pressing need for more diverse sampling both within and outside of Western cultures.

In sum, some theoretical perspectives and cultural narratives seem to portray daters as discerning consumers of the people they date. Dating is often conceptualized as a process of exhaustively searching through warehouses of potential partners, comparing each person's qualities to a set of ideals and methodically rejecting or abandoning each option whose criteria do not match. We suggest that we might get closer to understanding the nature of human relating by considering that romantic connection has a certain gravity that is so far difficult for researchers to predict, but nevertheless compels the progression of romantic relationships. 


\section{Acknowledgements}

This work was supported by Social Sciences and Humanities Research Council (SSHRC)

Insight grants awarded to Samantha Joel and Geoff MacDonald. The authors would like to thank Yoobin Park and James J. Kim for their insightful feedback on a previous draft.

\section{Conflict of Interest Statement}

The authors declare no conflicts of interest. 


\section{References}

Acevedo, B.P., \& Aron, A. (2014). Romantic love, pair-bonding, and the dopaminergic reward system.

Acevedo, B. P., Aron, A., Fisher, H. E., \& Brown, L. L. (2012). Neural correlates of long-term intense romantic love. Social Cognitive and Affective Neuroscience, 7, 145-159.

Ackerman, J. M., Griskevicius, V., \& Li, N. P. (2011). Let's get serious: Communicating commitment in romantic relationships. Journal of Personality and Social Psychology, $100,1079-1094$.

Allendorf, K., \& Ghimire, D. J. (2013). Determinants of marital quality in an arranged marriage society. Social Science Research, 42, 59-70.

Amato, P. R. (2010). Research on divorce: Continuing trends and new developments. Journal of Marriage and Family, 72, 650-666.

Anzani, A., Lindley, L., Tognasso, G., Galupo, M. P., \& Prunas, A. (2021). “Being talked to like I was a sex toy, like being transgender was simply for the enjoyment of someone else": Fetishization and sexualization of transgender and nonbinary individuals. Archives of Sexual Behavior, 50, 897-911.

Apostolou, M. (2007). Sexual selection under parental choice: The role of parents in the evolution of human mating. Evolution and Human Behavior, 28, 403-409.

Aragona, B. J., Liu, Y., Yu, Y. J., Curtis, J. T., Detwiler, J. M., Insel, T. R., \& Wang, Z. (2006). Nucleus accumbens dopamine differentially mediates the formation and maintenance of monogamous pair bonds. Nature Neuroscience, 9, 133-139.

Archer, J. (2000). Sex differences in aggression between heterosexual partners: A metaanalytic review. Psychological Bulletin, 126, 651-680. 
Arnocky, S., Woodruff, N., \& Schmitt, D. P. (2016). Men's sociosexuality is sensitive to changes in mate availability. Personal Relationships, 23, 172-181.

Aron, A., \& Aron, E. N. (1991). Love and sexuality. Sexuality in close relationships, 25-48.

Aron, A., Fisher, H., Mashek, D. J., Strong, G., Li, H., \& Brown, L. L. (2005). Reward, motivation, and emotion systems associated with early-stage intense romantic love. Journal of Neurophysiology, 94, 327-337.

Aron, A., Melinat, E., Aron, E. N., Vallone, R. D., \& Bator, R. J. (1997). The experimental generation of interpersonal closeness: A procedure and some preliminary findings. Personality and Social Psychology Bulletin, 23, 363-377.

Aron, A., Paris, M., \& Aron, E. N. (1995). Falling in love: Prospective studies of self-concept change. Journal of Personality and Social Psychology, 69, 1102-1112.

Arriaga, X. B. (2002). Joking violence among highly committed individuals. Journal of Interpersonal Violence, 17, 591-610.

Arriaga, X. B., Capezza, N. M., Goodfriend, W., Rayl, E. S., \& Sands, K. J. (2013). Individual well-being and relationship maintenance at odds: The unexpected perils of maintaining a relationship with an aggressive partner. Social Psychological and Personality Science, 4, 676-684.

Asendorpf, J. B., Penke, L., \& Back, M. D. (2011). From dating to mating and relating: Predictors of initial and long-term outcomes of speed-dating in a community sample. European Journal of Personality, 25, 16-30.

Baker, L. A., \& Emery, R. E. (1993). When every relationship is above average. Law and Human Behavior, 17, 439-450. 
Bartels, A., \& Zeki, S. (2000). The neural basis of romantic love. NeuroReport: For Rapid Communication of Neuroscience Research, 11, 3829-3834.

Bartels, A., \& Zeki, S. (2004). The neural correlates of maternal and romantic love. Neuroimage, 21, 1155-1166.

Batson, C. D., McMaster, M. R., Powell, A. L., Batson, J. G., Brandt, J. R., Dyck, J. L., \& Griffitt, C. (1988). Five studies testing two new egoistic alternatives to the empathy-altruism hypothesis. Journal of Personality and Social Psychology, 55, 52-77.

Battaglia, D. M., Richard, F. D., Datteri, D. L., \& Lord, C. G. (1998). Breaking up is (relatively) easy to do: A script for the dissolution of close relationships. Journal of Social and Personal Relationships, 15, 829-845.

Baumeister, R. F., \& Leary, M. R. (1995). The need to belong: Desire for interpersonal attachments as a fundamental human motivation. Psychological Bulletin, 117, 497529.

Baumeister, R. F., Wotman, S. R., \& Stillwell, A. M. (1993). Unrequited love: On heartbreak, anger, guilt, scriptlessness, and humiliation. Journal of Personality and Social Psychology, 64, 377-394.

Baxter, L. A., \& Wilmot, W. W. (1985). Taboo topics in close relationships. Journal of Social and Personal Relationships, 2, 253-269.

Beckes, L., \& Coan, J. A. (2011). Social baseline theory: The role of social proximity in emotion and economy of action. Social and Personality Psychology Compass, 5, 976988. 
Berscheid, E., Graziano, W., Monson, T., \& Dermer, M. (1976). Outcome dependency: Attention, attribution, and attraction. Journal of Personality and Social Psychology, 34, 978-989.

Birnbaum, G. E., \& Gillath, O. (2006). Measuring subgoals of the sexual behavioral system: What is sex good for? Journal of Social and Personal Relationships, 23, 675-701.

Birnbaum, G. E., Mizrahi, M., Kaplan, A., Kadosh, D., Kariv, D., Tabib, D., ... Burban, D. (2017). Sex unleashes your tongue: Sexual priming motivates self-disclosure to a new acquaintance and interest in future interactions. Personality and Social Psychology Bulletin, 43, 706-715.

Birnbaum, G. E., Reis, H. T., Mikulincer, M., Gillath, O., \& Orpaz, A. (2006). When sex is more than just sex: Attachment orientations, sexual experience, and relationship quality. Journal of Personality and Social Psychology, 91, 929-943.

Birnie, C., McClure, M. J., Lydon, J. E., \& Holmberg, D. (2009). Attachment avoidance and commitment aversion: A script for relationship failure. Personal Relationships, 16, 79-97.

Blair, K. L., \& Hoskin, R. A. (2019). Transgender exclusion from the world of dating: Patterns of acceptance and rejection of hypothetical trans dating partners as a function of sexual and gender identity. Journal of Social and Personal Relationships, 36, 2074-2095.

Bohns, V. K., \& DeVincent, L. A. (2019). Rejecting unwanted romantic advances is more difficult than suitors realize. Social Psychological and Personality Science, 10, 11021110.

Bowlby, J. (1969). Attachment. Attachment and loss: Vol. 1. Loss. New York: Basic Books. 
Bredow, C. A., Cate, R. A., \& Huston, T. L. (2008). Have we met before? A conceptual model of first romantic encounters. In S. Sprecher, A. Wenzel, \& J. Harvey (Eds.), Handbook of relationship initiation (p. 3-28). Psychology Press.

Brumbaugh, C. C., \& Fraley, R. C. (2010). Adult attachment and dating strategies: How do insecure people attract mates? Personal Relationships, 17, 599-614.

Burkett, J. P., Spiegel, L. L., Inoue, K., Murphy, A. Z., \& Young, L. J. (2011). Activation of $\mu-$ opioid receptors in the dorsal striatum is necessary for adult social attachment in monogamous prairie voles. Neuropsychopharmacology, 36, 2200-2210.

Burkett, J. P., \& Young, L. J. (2012). The behavioral, anatomical and pharmacological parallels between social attachment, love and addiction. Psychopharmacology, 224, $1-26$.

Buss, D. M. (1989). Sex differences in human mate preferences: Evolutionary hypotheses tested in 37 cultures. Behavioral and Brain Sciences, 12, 1-14.

Buss, D. M., \& Schmitt, D. P. (1993). Sexual strategies theory: An evolutionary perspective on human mating. Psychological Review, 100, 204-232.

Buunk, A. P., Park, J. H., \& Duncan, L. A. (2010). Cultural variation in parental influence on mate choice. Cross-Cultural Research: The Journal of Comparative Social Science, 44, 23-40.

Campbell, L., Chin, K., \& Stanton, S. C. E. (2016). Initial evidence that individuals form new relationships with partners that more closely match their ideal preferences. Collabra, 2, 2. 
Campbell, L., Pink, J. C., \& Stanton, S. C. (2015). Ideal mate standards and romantic relationships. In APA handbook of personality and social psychology, Volume 3: Interpersonal relations. (pp. 247-269). American Psychological Association.

Cameron, J. J., Stinson, D. A., Gaetz, R., \& Balchen, S. (2010). Acceptance is in the eye of the beholder: Self-esteem and motivated perceptions of acceptance from the opposite sex. Journal of Personality and Social Psychology, 99, 513-529.

Carter, R. M., MacInnes, J. J., Huettel, S. A., \& Adcock, R. A. (2009). Activation in the VTA and nucleus accumbens increases in anticipation of both gains and losses. Frontiers in Behavioral Neuroscience, 3, 15.

Cavallo, D. N., Tate, D. F., Ries, A. V., Brown, J. D., DeVellis, R. F., \& Ammerman, A. S. (2012). A social media-based physical activity intervention: A randomized controlled trial. American Journal of Preventive Medicine, 43, 527-532.

Charles, K. K., \& Luoh, M. C. (2010). Male incarceration, the marriage market, and female outcomes. The Review of Economics and Statistics, 92, 614-627.

Cheal, D. (2010). Canadian families today: New perspectives (2nd edition). Toronto: Oxford University Press.

Chopik, W. J., Edelstein, R. S., \& Fraley, R. C. (2013). From the cradle to the grave: Age differences in attachment from early adulthood to old age. Journal of Personality, 81, 171-183.

Chopik, W. J., \& Johnson, D. J. (2021). Modeling dating decisions in a mock swiping paradigm: An examination of participant and target characteristics. Journal of Research in Personality, 92. 
Clark, M. S., \& Mills, J. (1993). The difference between communal and exchange relationships: What it is and is not. Personality and Social Psychology Bulletin, 19, 684-691.

Clark, M. S., \& Beck, L. A. (2011). Initiating and evaluating close relationships: A task central to emerging adults. In F. D. Fincham \& M. Cui (Eds.), Advances in personal relationships. Romantic relationships in emerging adulthood (p. 190-212). Cambridge University Press.

Collins, N. L., \& Ford, M. (2010). Responding to the needs of others: The caregiving behavioral system in intimate relationships. Journal of Social and Personal Relationships, 27, 235-244.

Collins, T. J., \& Gillath, O. (2012). Attachment, breakup strategies, and associated outcomes: The effects of security enhancement on the selection of breakup strategies. Journal of Research in Personality, 46, 210-222.

Collins, L. M., \& Lanza, S. T. (2009). Latent class and latent transition analysis: With applications in the social, behavioral, and health sciences (Vol. 718). John Wiley \& Sons.

Conley, T. D., \& Collins, B. E. (2002). Gender, relationship status and stereotyping about sexual risk. Personality and Social Psychology Bulletin, 28, 1483-1494.

Dailey, R. M., Pfiester, A., Jin, B., Beck, G., \& Clark, G. (2009). On-again/off-again dating relationships: How are they different from other dating relationships? Personal Relationships, 16, 23-47. 
Dailey, R. M., Rossetto, K. R., Pfiester, A., \& Surra, C. A. (2009). A qualitative analysis of onagain/off-again romantic relationships: "It's up and down, all around”. Journal of Social and Personal Relationships, 26, 443-466.

Darley, J. M., \& Berscheid, E. (1967). Increased liking as a result of the anticipation of personal contact. Human Relations, 20, 29-40.

Day, M. V., Kay, A. C., Holmes, J. G., \& Napier, J. L. (2011). System justification and the defense of committed relationship ideology. Journal of Personality and Social Psychology, 101, 291-306.

DePaulo, B. M., \& Morris, W. L. (2005). Singles in society and in science. Psychological Inquiry, 16, 57-83.

Desai, S., \& Andrist, L. (2010). Gender scripts and age at marriage in India. Demography, 47, 667-687.

Diamond, L. M. (2003). What does sexual orientation orient? A biobehavioral model distinguishing romantic love and sexual desire. Psychological Review, 110, 173-192.

Diamond, L. M., Hicks, A. M., \& Otter-Henderson, K. (2008). Every time you go away: Changes in affect, behavior, and physiology associated with travel-related separations from romantic partners. Journal of Personality and Social Psychology, 95, 385-403.

Drigotas, S. M., \& Rusbult, C. E. (1992). Should I stay or should I go? A dependence model of breakups. Journal of Personality and Social Psychology, 62, 62-87.

Eastwick, P. W., \& Finkel, E. J. (2008). The attachment system in fledgling relationships: An activating role for attachment anxiety. Journal of Personality and Social Psychology, 95, 628-647. 
Eastwick, P. W., Finkel, E. J., \& Eagly, A. H. (2011). When and why do ideal partner preferences affect the process of initiating and maintaining romantic relationships? Journal of Personality and Social Psychology, 101, 1012-1032.

Eastwick, P. W., Finkel, E. J., \& Simpson, J. A. (2019). Best practices for testing the predictive validity of ideal partner preference-matching. Personality and Social Psychology Bulletin, 45, 167-181.

Eastwick, P. W., \& Hunt, L. L. (2014). Relational mate value: Consensus and uniqueness in romantic evaluations. Journal of Personality and Social Psychology, 106, 728.

Eastwick, P. W., Keneski, E., Morgan, T. A., McDonald, M. A., \& Huang, S. A. (2018). What do short-term and long-term relationships look like? Building the relationship coordination and strategic timing (ReCAST) model. Journal of Experimental Psychology: General, 147, 747-781.

Eisenberger, N. I., Lieberman, M. D., \& Williams, K. D. (2003). Does rejection hurt? An fMRI study of social exclusion. Science, 302, 290-292.

Fagundes, C. P., \& Schindler, I. (2012). Making of romantic attachment bonds: Longitudinal trajectories and implications for relationship stability. Personal Relationships, 19, 723-742.

Feingold, A. (1990). Gender differences in effects of physical attractiveness on romantic attraction: A comparison across five research paradigms. Journal of Personality and social psychology, 59, 981-993.

Festinger, L., Schachter, S., \& Back, K. (1950). Social pressures in informal groups; a study of human factors in housing. Harper. 
Finkel, E. J., \& Eastwick, P. W. (2009). Arbitrary social norms influence sex differences in romantic selectivity. Psychological Science, 20, 1290-1295.

Flake, J. K., Pek, J., \& Hehman, E. (2017). Construct validation in social and personality research: Current practice and recommendations. Social Psychological and Personality Science, 8, 370-378.

Fletcher, G. J. O., \& Kerr, P. S. G. (2010). Through the eyes of love: Reality and illusion in intimate relationships. Psychological Bulletin, 136, 627-658.

Fletcher, G. J. O., Kerr, P. S. G., Li, N. P., \& Valentine, K. A. (2014). Predicting romantic interest and decisions in the very early stages of mate selection: Standards, accuracy, and sex differences. Personality and Social Psychology Bulletin, 40, 540550.

Fletcher, G. J. O., Overall, N. C., \& Campbell, L. (2020). Reconsidering "best practices" for testing the ideal standards model: A response to Eastwick, Finkel, and Simpson (2018). Personality \& Social Psychology Bulletin.

Fletcher, G. J. O., \& Simpson, J. A. (2000). Ideal standards in close relationships: Their structure and functions. Current Directions in Psychological Science, 9, 102-105.

Fletcher, G. J. O., Simpson, J. A., Campbell, L., \& Overall, N. C. (2015). Pair-bonding, romantic love, and evolution: The curious case of Homo sapiens. Perspectives on Psychological Science, 10, 20-36.

Fletcher, G. J. O., Simpson, J. A., \& Thomas, G. (1999). Ideals in intimate relationships. Journal of Personality and Social Psychology, 76, 72-89. 
Fletcher, G. J. O., Simpson, J. A., \& Thomas, G. (2000). Ideals, perceptions, and evaluations in early relationship development. Journal of Personality and Social Psychology, 79, 933-940.

Flicker, S. M., Sancier-Barbosa, F., Afroz, F., Saif, S. N., \& Mohsin, F. (2020). Marital quality in arranged and couple-initiated marriages: The role of perceived influence over partner selection. International Journal of Psychology, 55, 629-637.

Florian, V., Mikulincer, M., \& Hirschberger, G. (2002). The anxiety-buffering function of close relationships: evidence that relationship commitment acts as a terror management mechanism. Journal of Personality and Social Psychology, 82, 527542.Fraley, R. C., Brumbaugh, C. C., \& Marks, M. J. (2005). The evolution and function of adult attachment: A comparative and phylogenetic analysis. Journal of Personality and Social Psychology, 89, 731-746.

Fraley, R. C., \& Waller, N. G. (1998). Adult attachment patterns: A test of the typological model. In J. A. Simpson \& W. S. Rholes (Eds.), Attachment theory and close relationships (p. 77-114). The Guilford Press.

Gagné, F.,M., \& Lydon, J. E. (2004). Bias and accuracy in close relationships: An integrative review. Personality and Social Psychology Review, 8, 322-338.

Galinsky, A. D., Hall, E. V., \& Cuddy, A. J. (2013). Gendered races: Implications for interracial marriage, leadership selection, and athletic participation. Psychological Science, 24, 498-506.

Gerlach, T. M., Arslan, R. C., Schultze, T., Reinhard, S. K., \& Penke, L. (2019). Predictive validity and adjustment of ideal partner preferences across the transition into romantic relationships. Journal of Personality and Social Psychology, 116, 313-330. 
Gere, J., \& Impett, E. A. (2018). Shifting priorities: Effects of partners' goal conflict on goal adjustment processes and relationship quality in developing romantic relationships. Journal of Social and Personal Relationships, 35, 793-810.

Gere, J., MacDonald, G., Joel, S., Spielmann, S. S., \& Impett, E. A. (2013). The independent contributions of social reward and threat perceptions to romantic commitment. Journal of Personality and Social Psychology, 105, 961-977.

Ghimire, D. J., Axinn, W. G., Yabiku, S. T., \& Thornton, A. (2006). Social change, premarital nonfamily experience, and spouse choice in an arranged marriage society. American Journal of Sociology, 111, 1181-1218.

Gillath, O., Mikulincer, M., Birnbaum, G. E., \& Shaver, P. R. (2008). When sex primes love: Subliminal sexual priming motivates relationship goal pursuit. Personality and Social Psychology Bulletin, 34, 1057-1069.

Gonzaga, G. C., Keltner, D., Londahl, E. A., \& Smith, M. D. (2001). Love and the commitment problem in romantic relations and friendship. Journal of Personality and Social Psychology, 81, 247-262.

Greitemeyer, T. (2009). Stereotypes of singles: Are singles what we think? European Journal of Social Psychology, 39, 368-383.

Guttentag, M., \& Secord, P. F. (1983). Too Many Women? The Sex Ratio Question. Sage Publications, Inc.

Hamid, S., Stephenson, R., \& Rubenson, B. (2011). Marriage decision making, spousal communication, and reproductive health among married youth in Pakistan. Global Health Action, 4, 5079. 
Harrison, M. A., \& Shortall, J. C. (2011). Women and men in love: Who really feels it and says it first? The Journal of Social Psychology, 151, 727-736.

Haruno, M., Kuroda, T., Doya, K., Toyama, K., Kimura, M., Samejima, K., ... Kawato, M. (2004). A neural correlate of reward-based behavioral learning in caudate nucleus: A functional magnetic resonance imaging study of a stochastic decision task. The Journal of Neuroscience, 24, 1660-1665.

Hazan, C., \& Diamond, L. M. (2000). The place of attachment in human mating. Review of General Psychology, 4, 186-204.

Hazan, C., \& Shaver, P. (1987). Romantic love conceptualized as an attachment process. Journal of Personality and Social Psychology, 52, 511-524.

Heffernan, M. E., Fraley, R. C., Vicary, A. M., \& Brumbaugh, C. C. (2012). Attachment features and functions in adult romantic relationships. Journal of Social and Personal Relationships, 29, 671-693.

Henrich, J., Heine, S. J., \& Norenzayan, A. (2010). Most people are not WEIRD: To understand human psychology, behavioural scientists must stop doing most of their experiments on Westerners. Nature, 466, 29.

Hertel, J., Schütz, A., DePaulo, B. M., Morris, W. L., \& Stucke, T. S. (2007). She’s single, so what? How are singles perceived compared with people who are married? Journal of Family Research, 19, 139-158.

Heu, L. C., Hansen, N., \& van Zomeren, M. (2021). Resolving the cultural loneliness paradox of choice: The role of cultural norms about individual choice regarding relationships in explaining loneliness in four European countries. Journal of Social and Personal Relationships. 
Hunt, L. L., Eastwick, P. W., \& Finkel, E. J. (2015). Leveling the playing field: Longer acquaintance predicts reduced assortative mating on attractiveness. Psychological Science, 26, 1046-1053.

Imamoğlu, E.O., Ads, M.M., \& Weisfeld, C.C. (2019). What is the impact of choosing one's spouse on marital satisfaction of wives and husbands? The case of arranged and self-choice Turkish marriages. Journal of Family Issues, 40, 1270 - 1298.

Inagaki, T. K. (2018). Opioids and social connection. Current Directions in Psychological Science, 27, 85-90.

Inagaki, T. K., Ray, L. A., Irwin, M. R., Way, B. M., \& Eisenberger, N. I. (2016). Opioids and social bonding: Naltrexone reduces feelings of social connection. Social Cognitive and Affective Neuroscience, 11, 728-735.

Joel, S., \& Eastwick, P. W. (2018). Intervening earlier: An upstream approach to improving relationship quality. Policy Insights from the Behavioral and Brain Sciences, 5, 25-32.

Joel, S., Eastwick, P. W., Allison, C. J., Arriaga, X. B., Baker, Z. G., Bar-Kalifa, E., ... \& Carmichael, C. L. (2020). Machine learning uncovers the most robust self-report predictors of relationship quality across 43 longitudinal couples studies. Proceedings of the National Academy of Sciences, 117, 19061-19071.

Joel, S., Eastwick, P. W., \& Finkel, E. J. (2017). Is romantic desire predictable? Machine learning applied to initial romantic attraction. Psychological Science, 28, 1478-1489. Joel, S., Gordon, A. M., Impett, E. A., MacDonald, G., \& Keltner, D. (2013). The things you do for me: Perceptions of a romantic partner's investments promote gratitude and commitment. Personality and Social Psychology Bulletin, 39, 1333-1345. 
Joel, S., Impett, E. A., Spielmann, S. S., \& MacDonald, G. (2018). How interdependent are Stay/Leave decisions? On staying in the relationship for the sake of the romantic partner. Journal of Personality and Social Psychology, 115, 805.

Joel, S., MacDonald, G., \& Page-Gould, E. (2018). Wanting to stay and wanting to go: Unpacking the content and structure of relationship stay/leave decision processes. Social Psychological and Personality Science, 9, 631-644.

Joel, S., Plaks, J. E., \& MacDonald, G. (2019). Nothing ventured, nothing gained: People anticipate more regret from missed romantic opportunities than from rejection. Journal of Social and Personal Relationships, 36, 305-336.

Joel, S., Spielmann, S. S., \& MacDonald, G. (2017). Motivated use of numerical anchors for judgments relevant to the self. Personality and Social Psychology Bulletin, 43, 972985.

Joel, S., Teper, R., \& MacDonald, G. (2014). People overestimate their willingness to reject potential romantic partners by overlooking their concern for other people. Psychological Science, 25, 2233-2240.

Johnson, Z. V., \& Young, L. J. (2015). Neurobiological mechanisms of social attachment and pair bonding. Current Opinion in Behavioral Sciences, 3, 38-44.

Jonason, P. K., Betes, S. L., \& Li, N. P. (2020). Solving mate shortages: Lowering standards, searching farther, and abstaining. Evolutionary Behavioral Sciences, 14, 160-172.

Jonason, P. K., Garcia, J. R., Webster, G. D., Li, N. P., \& Fisher, H. E. (2015). Relationship dealbreakers: Traits people avoid in potential mates. Personality and Social Psychology Bulletin, 4, 1697-1711. 
Kaestle, C. E. \& Halpern, C. T. (2005). Sexual activity among adolescents in romantic relationships with friends, acquaintances, or strangers. Archives of Pediatrics \& Adolescent Medicine, 159, 849-853.

Kline, G. H., Stanley, S. M., Markman, H. J., Olmos-Gallo, P. A., St. Peters, M., Whitton, S. W., \& Prado, L. M. (2004). Timing is everything: Pre-engagement cohabitation and increased risk for poor marital outcomes. Journal of Family Psychology, 18, 311-318.

Kreager, D. A., Cavanagh, S. E., Yen, J., \& Yu, M. (2014). "Where have all the good men gone?" gendered interactions in online dating. Journal of Marriage and Family, 76, 387-410.

Kurzban, R., \& Weeden, J. (2005). HurryDate: Mate preferences in action. Evolution and Human Behavior, 2, 227-244.

Kurzban, R., \& Weeden, J. (2007). Do advertised preferences predict the behavior of speed daters? Personal Relationships, 14, 623-632.

Le, B., \& Agnew, C. R. (2003). Commitment and its theorized determinants: A meta-analysis of the investment model. Personal Relationships, 10, 37-57.

Lee, L., Loewenstein, G., Ariely, D., Hong, J., \& Young, J. (2008). If I'm not hot, are you hot or not? Physical-attractiveness evaluations and dating preferences as a function of one's own attractiveness. Psychological Science, 19, 669-677.

LeRoy, A. S., Knee, C. R., Derrick, J. L., \& Fagundes, C. P. (2019). Implications for reward processing in differential responses to loss: Impacts on attachment hierarchy reorganization. Personality and Social Psychology Review, 23, 391-405.

Lichter, D. T., Price, J. P., \& Swigert, J. M. (2019). Mismatches in the marriage market. Journal of Marriage and Family, 82, 796-809. 
Li, N. P., Bailey, J. M., Kenrick, D. T., \& Linsenmeier, J. A. (2002). The necessities and luxuries of mate preferences: testing the tradeoffs. Journal of Personality and Social Psychology, 82, 947-955.

Li, N. P., Yong, J. C., Tov, W., Sng, O., Fletcher, G. J. O., Valentine, K. A., .. Balliet, D. (2013). Mate preferences do predict attraction and choices in the early stages of mate selection. Journal of Personality and Social Psychology, 105, 757-776.

Lindsay, J. M. (2000). An ambiguous commitment: Moving in to a cohabiting relationship. Journal of Family Studies, 6, 120-134.

Long, M. L.-W., \& Campbell, A. (2015). Female mate choice: A comparison between acceptthe-best and reject-the-worst strategies in sequential decision making. Evolutionary Psychology, 13, 1-6.

Luo, S., \& Zhang, G. (2009). What leads to romantic attraction: Similarity, reciprocity, security, or beauty? Evidence from a speed-dating study. Journal of Personality, 77, 933-964.

Luke, D. J., \& Oser, C. B. (2015). Ebony and ivory? Interracial dating intentions and behaviors of disadvantaged African American women in Kentucky. Social Science Research, 53, 338-350.

MacDonald, G., \& Leary, M. R. (2005). Why does social exclusion hurt? The relationship between social and physical pain. Psychological Bulletin, 131, 202-223.

MacDonald, T. K., \& Ross, M. (1999). Assessing the accuracy of predictions about dating relationships: How and why do lovers' predictions differ from those made by observers? Personality and Social Psychology Bulletin, 25, 1417-1429. 
MacDonald, G., \& Jessica, M. (2006). Family approval as a constraint in dependency regulation: Evidence from Australia and Indonesia. Personal Relationships, 13, 183194.

MacDonald, G., Marshall, T. C., Gere, J., Shimotomai, A., \& Lies, J. (2012). Valuing romantic relationships: The role of family approval across cultures. Cross-Cultural Research, 46, 366-393.

Machia, L. V., Proulx, M. L., Ioerger, M., \& Lehmiller, J. J. (2020). A longitudinal study of friends with benefits relationships. Personal Relationships, 27, 47-60.

Machin, A. J., \& Dunbar, R. I. M. (2011). The brain opioid theory of social attachment: A review of the evidence. Behaviour, 148, 987-1025.

Manning, W. D., \& Smock, P. J. (2005). Measuring and modeling cohabitation: New perspectives from qualitative data. Journal of Marriage and Family, 67, 989-1002.

Maxwell, J. A., Muise, A., MacDonald, G., Day, L. C., Rosen, N. O., \& Impett, E. A. (2017). How implicit theories of sexuality shape sexual and relationship well-being. Journal of Personality and Social Psychology, 112, 238-279.

McClure, M. J., Lydon, J. E., Baccus, J. R., \& Baldwin, M. W. (2010). A signal detection analysis of chronic attachment anxiety at speed dating: Being unpopular is only the first part of the problem. Personality and Social Psychology Bulletin, 36, 1024-1036.

McClure, M. J., \& Lydon, J. E. (2014). Anxiety doesn't become you: How attachment anxiety compromises relational opportunities. Journal of Personality and Social Psychology, $106,89-111$.

Mir, M. S., Wani, M. A., \& Sankar, R. (2016). Marital adjustment among love marriage and arranged marriage couples. The International Journal of Indian Psychology, 3, 51-56. 
Montoya, R. M. (2008). I'm hot, so I'd say you're not: The influence of objective physical attractiveness on mate selection. Personality and Social Psychology Bulletin, 34, $1315-1331$.

Morris, W. L., Sinclair, S., \& DePaulo, B. M. (2007). No shelter for singles: The perceived legitimacy of marital status discrimination. Group Processes \& Intergroup Relations, $10,457-470$.

Murray, S. L., Derrick, J. L., Leder, S., \& Holmes, J. G. (2008). Balancing connectedness and self-protection goals in close relationships: A levels-of-processing perspective on risk regulation. Journal of Personality and Social Psychology, 94, 429-459.

Murray, S. L., Holmes, J. G., \& Collins, N. L. (2006). Optimizing assurance: The risk regulation system in relationships. Psychological Bulletin, 132, 641-666.

Neff, L. A., \& Broady, E. F. (2011). Stress resilience in early marriage: Can practice make perfect? Journal of Personality and Social Psychology, 101, 1050-1067.

Neth, H., Schächtele, S., Duwal, S., \& Todd, P.M. (2011). Competitive mate choice: How need for speed beats quests for quality and harmony. CogSci.

Nordgren, L. F., Banas, K., \& MacDonald, G. (2011). Empathy gaps for social pain: Why people underestimate the pain of social suffering. Journal of Personality and Social Psychology, 100, 120-128.

OKCupid (2014). Race and attraction, 2009-2014. https://theblog.okcupid.com/race-andattraction-2009-2014-107dcbb4f060.

Ortigue, S., Bianchi-Demicheli, F., Hamilton, A. F., \& Grafton, S. T. (2007). The neural basis of love as a subliminal prime: An event-related functional magnetic resonance imaging study. Journal of Cognitive Neuroscience, 19, 1218-1230. 
Panksepp, J., Herman, B. H., Vilberg, T., Bishop, P., \& DeEskinazi, F. G. (1980). Endogenous opioids and social behavior. Neuroscience \& Biobehavioral Reviews, 4, 473-487.

Panksepp, J., \& Watt, D. (2011). Why does depression hurt? ancestral primary-process separation-distress (PANIC/GRIEF) and diminished brain reward (SEEKING) processes in the genesis of depressive affect. Psychiatry: Interpersonal and Biological Processes, 74, 5-13.

Park, Y., Impett, E. A., \& MacDonald, G. (2020). Singles' sexual satisfaction is associated with more satisfaction with singlehood and less interest in marriage. Personality and Social Psychology Bulletin, 47, 741-752.

Paulhus, D. L., \& Williams, K. M. (2002). The dark triad of personality: Narcissism, machiavellianism and psychopathy. Journal of Research in Personality, 36, 556-563.

Perilloux, C., \& Buss, D. M. (2008). Breaking up romantic relationships: Costs experienced and coping strategies deployed. Evolutionary Psychology, 6, 164-181.

Pistole, M. C., Clark, E. M., \& Tubbs, A. L. (1995). Love relationships: Attachment style and the investment model. Journal of Mental Health Counseling, 17, 199-209.

Raina, P., \& Maity, T. (2018). An empirical study on marital satisfaction between arranged and self marriage couples in Bangalore. International Journal of Indian Psychology, 6, 101-108.

Rand, D. G., Greene, J. D., \& Nowak, M. A. (2012). Spontaneous giving and calculated greed. Nature, 489, 427-430.

Ranzini, G., \& Rosenbaum, J. E. (2020). It's a match (?): Tinder usage and attitudes toward interracial dating. Communication Research Reports, 37, 44-54. 
Rhoades, G. K., Stanley, S. M., \& Markman, H. J. (2009). Couples' reasons for cohabitation: Associations with individual well-being and relationship quality. Journal of Family Issues, 30, 233-258.

Robnett, B., \& Feliciano, C. (2011). Patterns of racial-ethnic exclusion by internet daters. Social Forces, 89, 807-828.

Rossignac-Milon, M., Bolger, N., Zee, K. S., Boothby, E. J., \& Higgins, E. T. (2021). Merged minds: Generalized shared reality in dyadic relationships. Journal of Personality and Social Psychology, 120, 882-911.

Rusbult, C. E. (1980). Commitment and satisfaction in romantic associations: A test of the investment model. Journal of Experimental Social Psychology, 16, 172-186.

Rusbult, C. E. (1983). A longitudinal test of the investment model: The development (and deterioration) of satisfaction and commitment in heterosexual involvements. Journal of Personality and Social Psychology, 45, 101-117.

Rusbult, C. E., \& Martz, J. M. (1995). Remaining in an abusive relationship: An investment model analysis of nonvoluntary dependence. Personality and Social Psychology Bulletin, 21, 558-571.

Rusbult, C. E., \& Van Lange, Paul A. M. (2003). Interdependence, interaction and relationships. Annual Review of Psychology, 54, 351-375.

Rusbult, C. E., \& Van Lange, Paul A. M. (2008). Why we need interdependence theory. Social and Personality Psychology Compass, 2, 2049-2070.

Sassler, S. (2004). The process of entering into cohabiting unions. Journal of Marriage and Family, 66, 491-505. 
Sassler, S., \& Miller, A. J. (2011). Class differences in cohabitation processes. Family Relations: An Interdisciplinary Journal of Applied Family Studies, 60, 163-177.

Sbarra, D. A. (2006). Predicting the onset of emotional recovery following nonmarital relationship dissolution: Survival analyses of sadness and anger. Personality and Social Psychology Bulletin, 32, 298-312.

Schacht, R., \& Borgerhoff Mulder, M. (2015). Sex ratio effects on reproductive strategies in humans. Royal Society Open Science, 2.

Schindler, I., Fagundes, C. P., \& Murdock, K. W. (2010). Predictors of romantic relationship formation: Attachment style, prior relationships, and dating goals. Personal Relationships, 17, 97-105.

Schug, J., Alt, N. P., \& Klauer, K. C. (2015). Gendered race prototypes: Evidence for the nonprototypicality of Asian men and Black women. Journal of Experimental Social Psychology, 56, 121-125.

Segal, M. W. (1974). Alphabet and attraction: An unobtrusive measure of the effect of propinquity in a field setting. Journal of Personality and Social Psychology, 30, 654657.

Shanteau, J., \& Nagy, G. F. (1979). Probability of acceptance in dating choice. Journal of Personality and Social Psychology, 37, 522-533.

Sharabi, L. L., \& Dykstra-DeVette, T. (2019). From first email to first date: Strategies for initiating relationships in online dating. Journal of Social and Personal Relationships, 36, 3389-3407.

Slotter, E. B., \& Finkel, E. J. (2009). The strange case of sustained dedication to an unfulfilling relationship: Predicting commitment and breakup from attachment 
anxiety and need fulfillment within relationships. Personality and Social Psychology Bulletin, 35, 85-100.

Slotter, E. B., \& Gardner, W. L. (2012). The dangers of dating the "bad boy" (or girl): When does romantic desire encourage us to take on the negative qualities of potential partners? Journal of Experimental Social Psychology, 48, 1173-1178.

South, S. J., Trent, K., \& Shen, Y. (2001). Changing partners: Toward a macrostructuralopportunity theory of marital dissolution. Journal of Marriage and Family, 63, 743754.

South, S. J., \& Lloyd, K. M. (1995). Spousal alternatives and marital dissolution. American Sociological Review, 60, 21-35.

Spielmann, S. S., MacDonald, G., \& Tackett, J. L. (2012). Social threat, social reward, and regulation of investment in romantic relationships. Personal Relationships, 19, 601622.

Spielmann, S. S., MacDonald, G., Maxwell, J. A., Joel, S., Peragine, D., Muise, A., \& Impett, E. A. (2013). Settling for less out of fear of being single. Journal of Personality and Social Psychology, 105, 1049-1073.

Spielmann, S. S., Maxwell, J. A., MacDonald, G., \& Baratta, P. L. (2013). Don't get your hopes up: Avoidantly attached individuals perceive lower social reward when there is potential for intimacy. Personality and Social Psychology Bulletin, 39, 219-236.

Spielmann, S. S., MacDonald, G., Maxwell, J. A., Joel, S., Peragine, D., Muise, A., \& Impett, E. A. (2013). Settling for less out of fear of being single. Journal of personality and social psychology, 105, 1049. 
Spielmann, S. S., Maxwell, J. A., MacDonald, G., Peragine, D., \& Impett, E. A. (2020). The predictive effects of fear of being single on physical attractiveness and less selective partner selection strategies. Journal of Social and Personal Relationships, 37(1), 100123.

Stanley, S. M., Rhoades, G. K., \& Markman, H. J. (2006). Sliding versus deciding: Inertia and the premarital cohabitation effect. Family Relations: An Interdisciplinary Journal of Applied Family Studies, 55, 499-509.

Stinson, D. A., Cameron, J. J., \& Robinson, K. J. (2015). The good, the bad, and the risky: Selfesteem, rewards and costs, and interpersonal risk regulation during relationship initiation. Journal of Social and Personal Relationships, 32, 1109-1136.

Stone, E. A. (2019). Does mate scarcity affect marital choice and family formation? The evidence for new and classic formulations of sex ratio theory. Marriage \& Family Review, 55, 403-422.

Tan, R., Overall, N. C., \& Taylor, J. K. (2012). Let's talk about us: Attachment, relationshipfocused disclosure, and relationship quality. Personal Relationships, 19, 521-534.

Taylor, L.S., Fiore, A. T., Mendelsohn, G. A., \& Cheshire, C. (2011). “Out of my league”: a realworld test of the matching hypothesis. Personality and Social Psychology Bulletin, 37, 942-954.

Taylor, P. (2010). The decline of marriage and rise of new families (Social \& Demographic Trends report). Washington, DC: Pew Research Center.

Tchalova, K., \& MacDonald, G. (2020). Opioid receptor blockade inhibits self-disclosure during a closeness-building social interaction. Psychoneuroendocrinology, 113, 10. 
Tennov, D. (1979). Love and limerence: The experience of being in love. New York: Stein and Day.

Thibaut, J. W., \& Kelley, H. H. (1959). The social psychology of groups. New York: John Wiley. Timmermans, E., \& Courtois, C. (2018). From swiping to casual sex and/or committed relationships: Exploring the experiences of Tinder users. Information Society, 34, 5970.

Todd, P.M. (1997). Searching for the next best mate. In Simulating social phenomena (pp. 419-436). Springer, Berlin, Heidelberg.

Todd, P. M., Penke, L., Fasolo, B., \& Lenton, A. P. (2007). Different cognitive processes underlie human mate choices and mate preferences. PNAS Proceedings of the National Academy of Sciences of the United States of America, 104, 15011-15016.

Tracy, J. L., Shaver, P. R., Albino, A. W., \& Cooper, M. L. (2003). Attachment styles and adolescent sexuality. In P. Florsheim (Ed.), Adolescent romantic relations and sexual behavior: Theory, research, and practical implications (pp. 137-159). Mahwah, NJ: Lawrence Erlbaum Associates Publishers.

Tran, P., Judge, M., \& Kashima, Y. (2019). Commitment in relationships: An updated metaanalysis of the Investment Model. Personal Relationships, 26, 158-180.

Trivers, R. L. (1972). Parental Investment and Sexual Selection. In B. Campbell (Ed.), Sexual Selection and the Descent of Man, 1871-1971 (pp. 136-179). Chicago, IL: Aldine.

Tyler, T. R., \& Sears, D. O. (1977). Coming to like obnoxious people when we must live with them. Journal of Personality and Social Psychology, 35, 200-211. 
VanderDrift, L. E., Agnew, C. R., \& Wilson, J. E. (2009). Nonmarital romantic relationship commitment and leave behavior: The mediating role of dissolution consideration. Personality and Social Psychology Bulletin, 35, 1220-1232.

Vorauer, J. D., Cameron, J. J., Holmes, J. G., \& Pearce, D. G. (2003). Invisible overtures: Fears of rejection and the signal amplification bias. Journal of Personality and Social Psychology, 84, 793-812.

Vorauer, J. D., \& Ratner, R. K. (1996). Who's going to make the first move? Pluralistic ignorance as an impediment to relationship formation. Journal of Social and Personal Relationships, 13, 483-506.

Walker, R. S., Hill, K. R., Flinn, M. V., \& Ellsworth, R. M. (2011). Evolutionary history of hunter-gatherer marriage practices. PloS One, 6, Article e19066.

Walster, E., Aronson, V., Abrahams, D., \& Rottman, L. (1966). Importance of physical attractiveness in dating behavior. Journal of Personality and Social Psychology, 4, 508-516.

Wang, W., \& Parker, K. (2014). Record share of Americans have never married: As values, economics, and gender patterns change (Social \& Demographic Trends report). Washington, DC: Pew Research Center.

Wiederman, M. W. (2005). The gendered nature of sexual scripts. The Family Journal, 13, 496-502.

Williams, K. D., Cheung, C. K., \& Choi, W. (2000). Cyberostracism: effects of being ignored over the Internet. Journal of Personality and Social Psychology, 79, 748-762. 
Williamson, H. (2021, January). Meta-research on relationship science: A focus on diversity and inclusion. Talk presented at the annual meeting of the Society for Personality and Social Psychology.

Xiaohe, X. \& Whyte, M. K. (1990). Love matches and arranged marriages: A Chinese replication. Journal of Marriage and the Family, 52, 709-722.

Xu, X., Aron, A., Brown, L., Cao, G., Feng, T., \& Weng, X. (2011). Reward and motivation systems: A brain mapping study of early-stage intense romantic love in Chinese participants. Human Brain Mapping, 32, 249-257.

Yamagishi, T., Li, Y., Takagishi, H., Matsumoto, Y., \& Kiyonari, T. (2014). In search of Homo economicus. Psychological Science, 25, 1699-1711.

Yelsma, P. \& Athappilly, K. (1988). Marital satisfaction and communication practices: Comparisons among Indian and American couples. Journal of comparative family studies, 19, 37-54.

Zaidi, A. U., \& Shuraydi, M. (2002). Perceptions of arranged marriages by young Pakistani Muslim women living in a Western society. Journal of Comparative Family Studies, 33, 495-514. 